\title{
Designing Broadband over Power Lines Networks Using the Techno-Economic Pedagogical (TEP) Method - Part II: Overhead Low-Voltage and Medium-Voltage Channels and Their Modal Transmission Characteristics
}

\author{
Athanasios G. Lazaropoulos 1,2,* \\ 1: School of Electrical and Computer Engineering, National Technical University of Athens (NTUA), \\ 9 Iroon Polytechniou Street, Zografou, Athens, Greece 15780 \\ 2: Department of Electrical and Electronic Engineering Educators, School of Pedagogical and \\ Technological Education (ASPETE), Station Eirini HSAP, Heraklio Attikis, Athens, Greece 14121
}

Received February 8, 2015; Accepted March 25, 2015; Published April 11, 2015

\begin{abstract}
Based on the techno-economic pedagogical (TEP) method proposed in [1] that is suitable for designing Broadband over Power Lines (BPL) networks in transmission and distribution power grids, this paper examines the broadband potential of overhead low-voltage/broadband over power lines (LV/BPL) and medium-voltage/broadband over power lines (MV/BPL) networks.

In this paper, on the basis of the set of linear simplifications and technoeconomic metrics already presented in [1], TEP method demonstrates to undergraduate electrical and computer engineering (ECE) students the behavior of overhead LV/BPL and MV/BPL networks in terms of their modal transmission characteristics when different overhead LV/BPL and MV/BPL topologies occur.

The contribution of this paper is four-fold. First, the factors influencing modal transmission characteristics of overhead LV/BPL and MV/BPL networks are investigated with regard to their spectral behavior and end-to-end channel attenuation. Second, the impact of the multiplicity of branches at the same junction is first examined. In the light of cascaded two-way power dividers, TEP method is extended so as to cope with more complex BPL topologies offering a new simplified and accurate circuital approximation. Third, apart from the broadband transmission characteristics of the entire overhead distribution power grid, a consequence of the application of TEP method is that it helps towards the intraoperability/interoperability of overhead LV/BPL and MV/BPL systems under a common PHY framework in the concept of a unified distribution smart grid (SG) power network. Fourth, TEP method can be demonstrated to undergraduate ECE students as case study in order to stimulate their interest for Microwave Engineering and Circuit/System Engineering courses.
\end{abstract}

Keywords: Education, Educational Policy; Comparative Education; Faculty of Electrical and Computer Engineering; Microwave Engineering; Engineering Economics; Broadband over Power Lines (BPL) modeling; eigenvalue decomposition (EVD) modal analysis; Power Line Communications (PLC); overhead Low-Voltage (LV) power lines; overhead Medium-Voltage (MV) power lines 


\section{Introduction}

The need of bridging the digital gap between underdeveloped and developed areas signals the green light towards the deployment of broadband over power lines (BPL) networks across transmission -i.e., high-voltage (HV)- and distribution-i.e., low-voltage (LV) and medium-voltage (MV)- power grids [1]-[9]. Due to the ubiquitous nature of transmission and distribution power grids, BPL technology can offer real time information at any point of the entire power grid transforming it into an advanced IP-based interactive smart grid (SG) service network with a myriad of potential SG applications [10]-[14]. Recent findings demonstrate that the entire overhead distribution power grid may operate as an excellent communications medium offering low-loss characteristics, flat-fading features and low multipath dispersion on the vicinity of every power consumer [15]-[18].

To study overhead LV/BPL and MV/BPL networks, it is obvious that the development of efficient and accurate models to describe signal transmission at high frequencies across them is a challenging venture and imperative necessity. The behavior of BPL transmission channels installed on LV and MV multiconductor transmission line (MTL) structures is examined by employing the well-known hybrid method [3]. Briefly mentioned in [1], [63], this hybrid method follows: (i) a bottom-up approach consisting of an appropriate combination of the similarity transformation and MTL theory to determine the propagation constant and the characteristic impedance of the modes supported [19]-[23]; and (ii) a top-down approach -i.e., TM2 method- that is based on the concatenation of multidimensional $T$-matrices of network modules to evaluate the end-to-end channel attenuation of BPL connections [2], [3], [5], [19], [22], [24]-[26].

Although the hybrid method is characterized by experimental validation and high accuracy, it presents high complexity and demands advanced knowledge in Microwave and Circuit/System engineering so as to be understandable to ECE students. As it has already been mentioned in [1], [63], the set of linear simplifications allows the transformation of the complicated hybrid method into the straightforward technoeconomic pedagogical (TEP) method without seriously affecting the validity and the accuracy of the used techno-economic metrics. Therefore, TEP method promotes the interaction between Microwave Engineering and Circuit/System Engineering courses facilitating the understanding of ECE students.

In contrast with overhead HV/BPL networks, overhead LV/BPL and MV/BPL networks are characterized by a significant variety of occurred topologies. This system peculiarity urges the need of upgrading the TEP method of [1], [63] so as to deal with different network topologies. Therefore, TEP method needs to be integrated with TM2 method of top-down approach of the hybrid method. Apart from a clear and consistent theoretical approach, this extended edition of TEP method is flexible and accurate determining, consequently, any changes of the transfer characteristics related to relevant factors of the system configuration in the 1-100 MHz frequency band. The influence of factors, such as the overhead power grid type -either LV or MV system configuration-, the physical properties of the conductors used, the MTL configuration, the end-to-end distance and the number, the electrical length, the terminations and the multiplicity of the branches encountered along the end-to-end BPL signal propagation are investigated based on numerical results concerning various simulated overhead LV/BPL and MV/BPL topologies. As it has already been presented in [1], [63], since the behavior of overhead BPL networks mainly depends on the behavior of modes supported by the examined overhead MTL configurations, the main interest of this paper is to highlight to ECE 
students the influence of the aforementioned factors to modal channels of overhead LV and MV MTL configurations.

Through the comparative analysis of the numerical results of overhead distribution power grids, the common nature of overhead LV/BPL and MV/BPL networks is outlined to ECE students allowing their common handling as it concerns the BPL signal transmission through their power lines. On the basis of a unified PHY framework and in the light of cascaded two-way power dividers, TEP method further approximates end-to-end channel attenuation of each overhead BPL distribution network.

The applied transmission analysis reveals the low-loss nature of overhead BPL systems regardless of the overhead distribution power grid type and topology. A consequence of the proposed modeling is that it can facilitate the process of coexistence of overhead LV/BPL with MV/BPL systems; a preliminary step toward the intraoperability/interoperability of BPL systems in a SG environment.

The rest of this paper is organized as follows: In Section II, the overhead LV and MV configurations adopted in this paper are presented. Section III synopsizes the MTL theory and eigenvalue decomposition (EVD) modal analysis concerning overhead $\mathrm{LV} / \mathrm{BPL}$ and MV/BPL transmission. In Section IV, numerical results are provided, aiming at marking out how the various features of the overhead distribution power grid influence BPL transmission. The common nature of overhead LV/BPL and MV/BPL systems is revealed permitting their further common PHY handling. Section V concludes the paper.

\section{Overhead LV and MV Distribution power Networks}

Either the overhead or the underground power grids are employed for new urban, suburban, and rural distribution power grid installations. The selection between overhead or underground power grid installation is made according to different technoeconomic criteria like cost requirements, existing grid topology and urban plan constraints. Overhead lines are essentially used in areas where the relatively low density of the population cannot justify the high cost of underground lines [27]-[29].

Since the power grid was not originally designed to serve the purpose of a transmission medium for communication signals, the overhead distribution power grids are subjected to the main aggravating factors that are attenuation, multipath due to various reflections, multimode propagation, noise and electromagnetic interference [2]-[7], [17], [24], [30]-[36]. Especially, as it concerns the multimode propagation, due to the assumption of the quasi-TEM mode of propagation, the traditional transmission-line (TL) theory is appropriate to model BPL propagation in the overhead case [30], [43], [53]. Good agreement between BPL models that are based on TL theory and a series of experiments [61], [62] has been confirmed for frequencies up to $100 \mathrm{MHz}$, motivating either the extensive use of BPL models that are based on TL theory or the neglect of the higher-order modes of propagation that occur in the $\mathrm{MHz}$ frequency range. Except for the signal propagation and transmission drawbacks, in real distribution power grids, a number of "real life" anomalies further degrade the theoretical broadband communications performance of overhead power distribution grids: (i) overhead distribution poles do not only carry power distribution lines, but they also support street lighting and telecommunications cables, which are located near to overhead distribution lines, influencing BPL signal propagation; (ii) the presence of relatively large pole-mounted capacitor banks, MV/LV transformers, traps, shunt capacitors, and bypass 
devices, which are mainly metallic elements, critically affect the BPL signal transmission; and (iii) neutral grounding and/or grounding of the wooden support poles and/or grounding of surge-diverters that are often provided by the utilities so as to deal with lightning strikes and voltage upsurges influence BPL system broadband potential. Hence, during the deployment of BPL networks in the "real life", these additional practical aggravating factors must be accounted for in the modeling or else the simulations and theoretical results may be proven to be optimistic [14], [25], [37]. Anyway, the analysis of this paper that has pedagogical purposes focuses on the basic theoretical analysis rather than "real network" problems [2], [25], [28]-[32], [35], [38]-[41].

A typical case of overhead LV distribution line is depicted in Fig. 1(a). Four non-insulated conductors are suspended one above the other spaced by $\Delta_{L V}$ in the range from $0.3 \mathrm{~m}$ to $0.5 \mathrm{~m}$ and located at heights $h_{L V}$ ranging from $6 \mathrm{~m}$ to $10 \mathrm{~m}$ above ground for the lowest conductor. The upper conductor is the neutral, while the lower three conductors are the three phases. This three-phase four-conductor overhead LV distribution line configuration is considered in the present work consisting of ASTER $1 \times 34.4 \mathrm{~mm}^{2}+3 \times 54.6 \mathrm{~mm}^{2}$ conductors [3], [21], [27], [28], [39]-[43].

Overhead MV distribution lines hang at typical heights $h_{M V}$ ranging from $8 \mathrm{~m}$ to $10 \mathrm{~m}$ above ground. Typically, three parallel non-insulated phase conductors spaced by $\Delta_{M V}$ in the range from $0.3 \mathrm{~m}$ to $1 \mathrm{~m}$ are used above lossy ground. This three-phase three-conductor overhead MV distribution line configuration is considered in the present work consisting of ACSR $3 \times 95 \mathrm{~mm}^{2}$ conductors -see Fig. 1(b)- [2]-[4], [25], [27], [28], [32], [39]-[41].

The ground is considered as the reference conductor. The conductivity of the ground is assumed $\sigma_{g}=5 \mathrm{mS} / \mathrm{m}$ and its relative permittivity $\varepsilon_{r g}=13$, which is a realistic scenario [2]-[7], [25], [32], [33]. The impact of imperfect ground on signal propagation over power lines was analyzed in [2], [4], [25], [32], [37], [39]-[41], [44]-[47].

\section{MTL Theory and EVD Modal Analysis}

As it has already been reported in [1]-[7], [12]-[14], [24], [30]-[33], [48], [49], [63], through a matrix approach, the standard TL analysis can be extended to the MTL case. MTL case involves more than two conductors. An MTL structure, which supports $n+1$ conductors parallel to the $z$ axis, as depicted in Figs. 1(a) and 1(b), may support $n$ pairs of forward- and backward-traveling waves with corresponding propagation constants. A coupled set of $2 n$ first-order partial differential equations that relates the line voltages $V_{i}(z, t), i=1, \ldots, n$ to the line currents $I_{i}(z, t), i=1, \ldots, n$ may describe these forward- and backward-traveling waves. Each pair of these waves is referred to as a mode [2], [12]-[14], [21], [30]-[32].

Therefore, in the case of overhead $\operatorname{LV}\left(n^{\mathrm{LV}}=4\right)$ and MV $\left(n^{\mathrm{MV}}=3\right)$ distribution power lines over lossy plane ground, it was found that $n^{X V}$ modes are supported [2], [12][14], [19]-[22], [25], [27], [28], [32], [37], [42], [45]-[47]: 


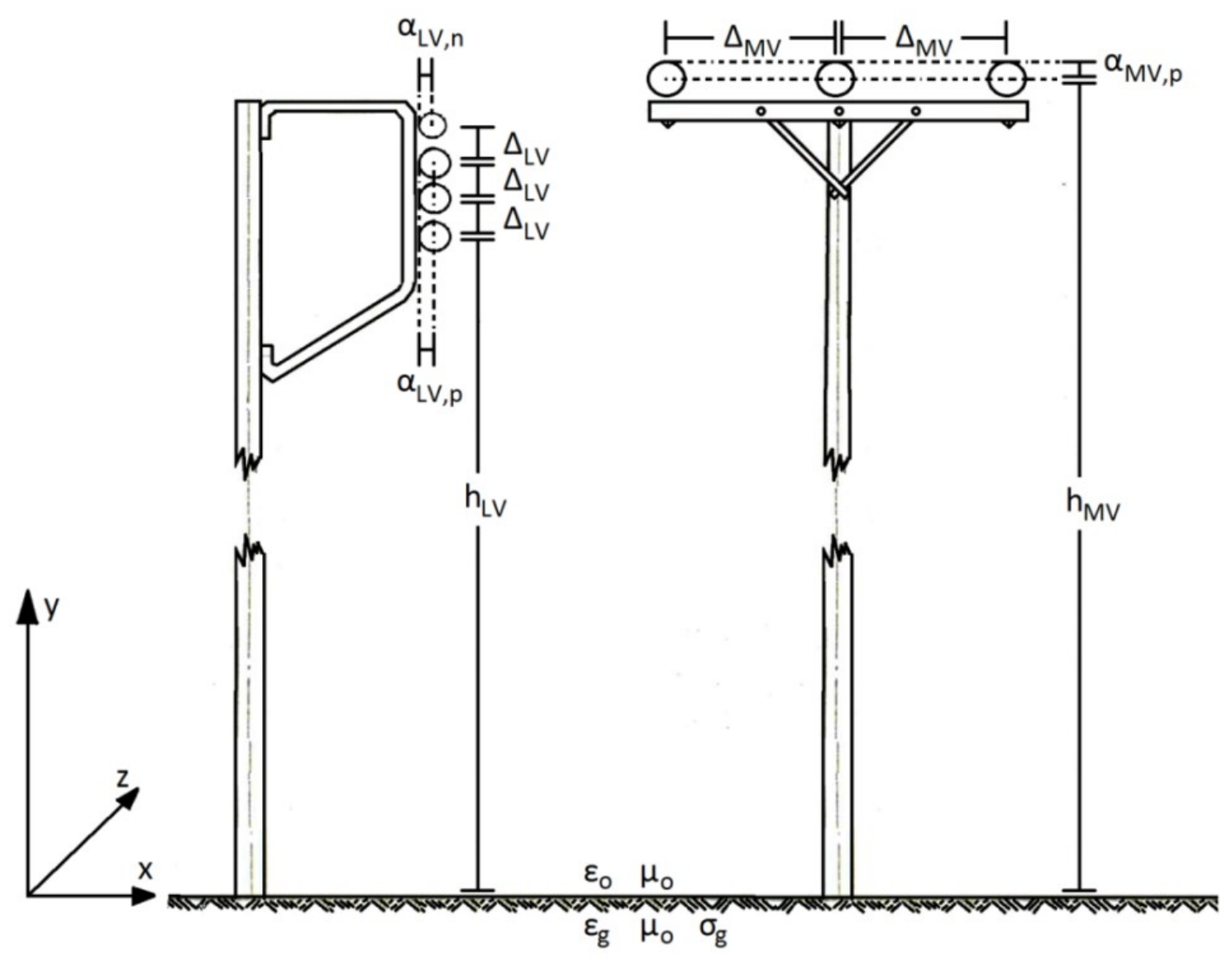

(a)

(b)

Figure 1. Typical overhead multiconductor structures [2], [3]. (a) LV. (b) MV.

- Common mode of overhead BPL transmission $\left(\mathrm{CM}^{X V}\right)$ which propagates via the $n$ conductors and returns via the ground where $[\cdot]^{X V}$ indicates the overhead power grid type examined -either LV or MV grid-. $\gamma_{\mathrm{CM}}^{X V}$ constitutes the $\mathrm{CM}^{X V}$ propagation constant.

- Differential modes of overhead BPL transmission $\left(\mathrm{DM}_{i}^{X V}, i=1, \ldots, n^{X V}-1\right)$ which propagate and return via the $n$ conductors. $\gamma_{\mathrm{DM} i}^{X V}, i=1, \ldots, n^{X V}-1$ constitute the propagation constants of $\mathrm{DM}_{i}^{X V}, i=1, \ldots, n^{X V}-1$, respectively.

Similarly to [1], [63], to bypass the complicated propagation analysis of the bottom-up approach of the hybrid method and to increase the ECE students' understanding of the following analysis, TEP method proposes that the attenuation coefficients and the phase delays of the CM and the DMs can be replaced by their respective linear approximations with satisfactory accuracy. More specifically, the modal attenuation coefficients can be replaced by their respective mean values while the modal phase delays can be replaced by their respective linear regressions.

The attenuation coefficients $\alpha_{\mathrm{CM}}^{\mathrm{LV}}=\operatorname{Re}\left\{\gamma_{\mathrm{CM}}^{\mathrm{LV}}\right\}, \quad \alpha_{\mathrm{DM} i}^{\mathrm{LV}}=\operatorname{Re}\left\{\gamma_{\mathrm{DM} i}^{\mathrm{LV}}\right\}, i=1,2,3$, $\alpha_{\mathrm{CM}}^{\mathrm{MV}}=\operatorname{Re}\left\{\gamma_{\mathrm{CM}}^{\mathrm{MV}}\right\}$, and $\alpha_{\mathrm{DM} j}^{\mathrm{MV}}=\operatorname{Re}\left\{\gamma_{\mathrm{DM} j}^{\mathrm{MV}}\right\}, j=1,2$ of the $\mathrm{CM}^{\mathrm{LV}}$, the three $\mathrm{DM}^{\mathrm{LV}} \mathrm{s}$, the $\mathrm{CM}^{\mathrm{MV}}$ 
and the two $\mathrm{DM}^{\mathrm{MV}} \mathrm{s}$, respectively, are evaluated using the bottom-up approach of the hybrid method and are plotted versus frequency in Fig. 2(a) for the configurations depicted in Figs. 1(a) and 1(b). In Figs. 2(b)-(d), the absolute values of attenuation coefficient differences are also given versus frequency in the cases of: (i) $\mathrm{CM}^{\mathrm{LV}}$ and $\mathrm{CM}^{\mathrm{MV}}$; (ii) $\mathrm{DM}_{1}^{\mathrm{LV}}$ and $\mathrm{DM}_{1}^{\mathrm{MV}}$; and (iii) $\mathrm{DM}_{2}^{\mathrm{LV}}$ and $\mathrm{DM}_{2}^{\mathrm{MV}}$, respectively, when the bottom-up approach of the hybrid method is adopted. In Figs. 2(e)-(h), the same plots are given when the TEP method is applied.

The phase delays $\beta_{C M}^{L V}=\operatorname{Im}\left\{\gamma_{\mathrm{CM}}^{\mathrm{LV}}\right\}, \beta_{\mathrm{DM} i}^{\mathrm{LV}}=\operatorname{Im}\left\{\gamma_{\mathrm{DM} i}^{\mathrm{LV}}\right\}, i=1,2,3, \beta_{\mathrm{CM}}^{\mathrm{MV}}=\operatorname{Im}\left\{\gamma_{\mathrm{CM}}^{\mathrm{MV}}\right\}$, and $\beta_{\mathrm{DM} j}^{\mathrm{MV}}=\operatorname{Im}\left\{\gamma_{\mathrm{DM} j}^{\mathrm{MV}}\right\}, j=1,2$ of the $\mathrm{CM}^{\mathrm{LV}}$, the three $\mathrm{DM}^{\mathrm{LV}} \mathrm{s}$, the $\mathrm{CM}^{\mathrm{MV}}$ and the two $\mathrm{DM}^{\mathrm{MV}} \mathrm{s}$, respectively, are linear functions of frequency, coincide and are plotted versus frequency in Fig. 3(a) for the configurations depicted in Figs. 1(a) and 1(b) when the bottom-up approach of the hybrid method is adopted. In Figs. 3(b)-(d), the absolute values of phase delay differences are also given versus frequency in the cases of: (i) $\mathrm{CM}^{\mathrm{LV}}$ and $\mathrm{CM}^{\mathrm{MV}}$; (ii) $\mathrm{DM}_{1}^{\mathrm{LV}}$ and $\mathrm{DM}_{1}^{\mathrm{MV}}$; and (iii) $\mathrm{DM}_{2}^{\mathrm{LV}}$ and $\mathrm{DM}_{2}^{\mathrm{MV}}$, respectively, when the bottom-up approach of the hybrid method is adopted. In Figs. 3(e)-(h), the same plots are given when the TEP method is applied.

As far as the spectral behavior of the modes is concerned, the following characteristics should be noted.

- As it concerns overhead BPL propagation in overhead LV and MV MTL configurations, according to the hybrid method, in the lower part of the frequency spectrum - up to approximately $20 \mathrm{MHz}-$, the attenuation of the $\mathrm{CM}^{X V} \mathrm{~s}$ is higher compared to that of the $\mathrm{DM}^{X V}$. At frequencies above $20 \mathrm{MHz}$, propagation takes place entirely above the ground as in the lossless case. Therefore, the $\mathrm{CM}^{X V} \mathrm{~S}$ and the $\mathrm{DM}^{X V_{\mathrm{S}}}$ coexist resulting to multimode propagation [2], [12], [14], [32], [45]-[47]. Similarly to [1], [63], TEP method provides an adequate approximation of the behavior of modal attenuation coefficients that, however, facilitates the ECE students to the following circuit analysis. Anyway, the occurred differences between hybrid and TEP method slightly affect the generality of the following analysis (see also in Section IV).

- The phase delays of $\mathrm{CM}^{X V}$ and $\mathrm{DM}^{X V}$ s exhibit a linear behavior with respect to frequency across the entire frequency range $1-100 \mathrm{MHz}$ and depend mainly on the surrounding media (air) properties. This almost identical spectral behavior of phase delays has also been observed in overhead and underground MV/BPL and HV/BPL transmission [1], [2], [12], [14], [32], [45]-[47]. Based on the results of the linear regression, TEP method accurately describes the behavior of modal phase delays.

- In accordance with the hybrid method, the plots corresponding to the spectral behavior of the difference between $\mathrm{CM}^{\mathrm{LV}}$ and $\mathrm{CM}^{\mathrm{MV}}$ reveal the close behavior of $\mathrm{CM}^{X V}$ s. The slight divergence existing between $\mathrm{CM}^{\mathrm{LV}}$ and $\mathrm{CM}^{\mathrm{MV}}$ is attributed to the differences between the overhead LV and MV configurations considered in the present paper. As to $\mathrm{DM}^{X V}$ S of overhead BPL transmission, since the relevant 

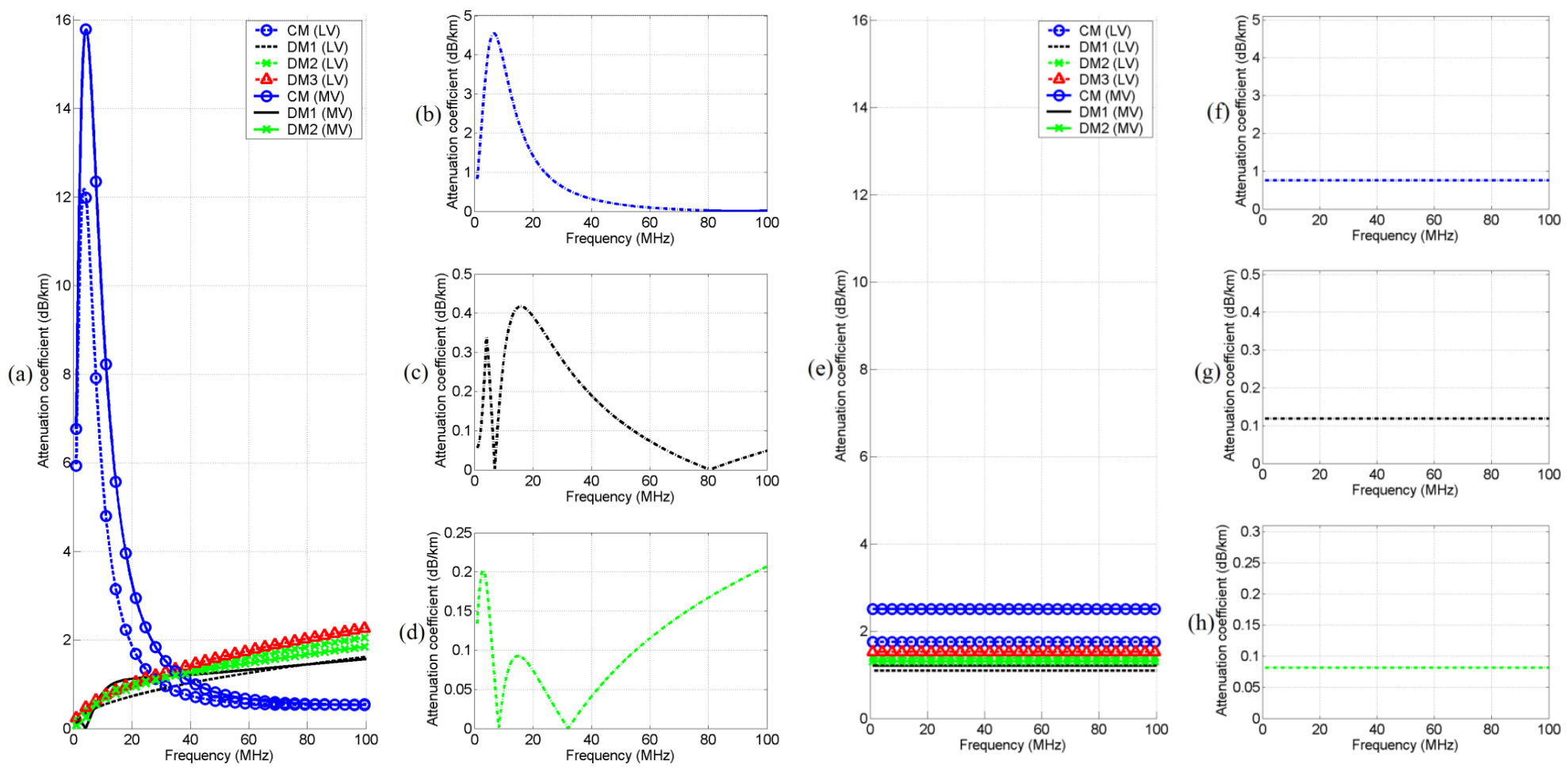

Figure 2. Attenuation coefficients of overhead LV/BPL and MV/BPL distribution lines when hybrid and TEP methods are applied (the subchannel frequency spacing is equal to $0.1 \mathrm{MHz}$ ). (a) All the modes -hybrid method-. (b) Difference between $\mathrm{CM}^{\mathrm{LV}}$ and $\mathrm{CM}^{\mathrm{MV}}$-hybrid method-. (c) Difference between $\mathrm{DM}_{1}^{\mathrm{LV}}$ and $\mathrm{DM}_{1}^{\mathrm{MV}}$-hybrid method-. (d) Difference between $\mathrm{DM}_{2}^{\mathrm{LV}}$ and $\mathrm{DM}_{2}^{\mathrm{MV}}$-hybrid method-. (e) All the modes -TEP method-. (f) Difference between $\mathrm{CM}^{\mathrm{LV}}$ and $\mathrm{CM}^{\mathrm{MV}}$-TEP method-. (g) Difference between $\mathrm{DM}_{1}^{\mathrm{LV}}$ and $\mathrm{DM}_{1}^{\mathrm{MV}}-\mathrm{TEP}$ method-. (h) Difference between $\mathrm{DM}_{2}^{\mathrm{LV}}$ and $\mathrm{DM}_{2}^{\mathrm{MV}}-\mathrm{TEP}$ method-.

influence of the lossy ground is negligible, the spectral behaviors of $\mathrm{DM}^{X V} \mathrm{~S}$ are very close to each other; their curves are almost identical either between DMs of the same overhead power grid type or between DMs of different distribution power grids. According to TEP method, the basic differences between the aforementioned modes are maintained so that ECE students could recognize the effect of MTL configurations and ground/air properties to the propagation phenomena.

- As usually done to simplify the analysis [2]-[7], [12]-[14], [24], [30]-[33], due to their almost identical spectral behavior, only one DM of the same overhead power grid type will be examined, hereafter. 

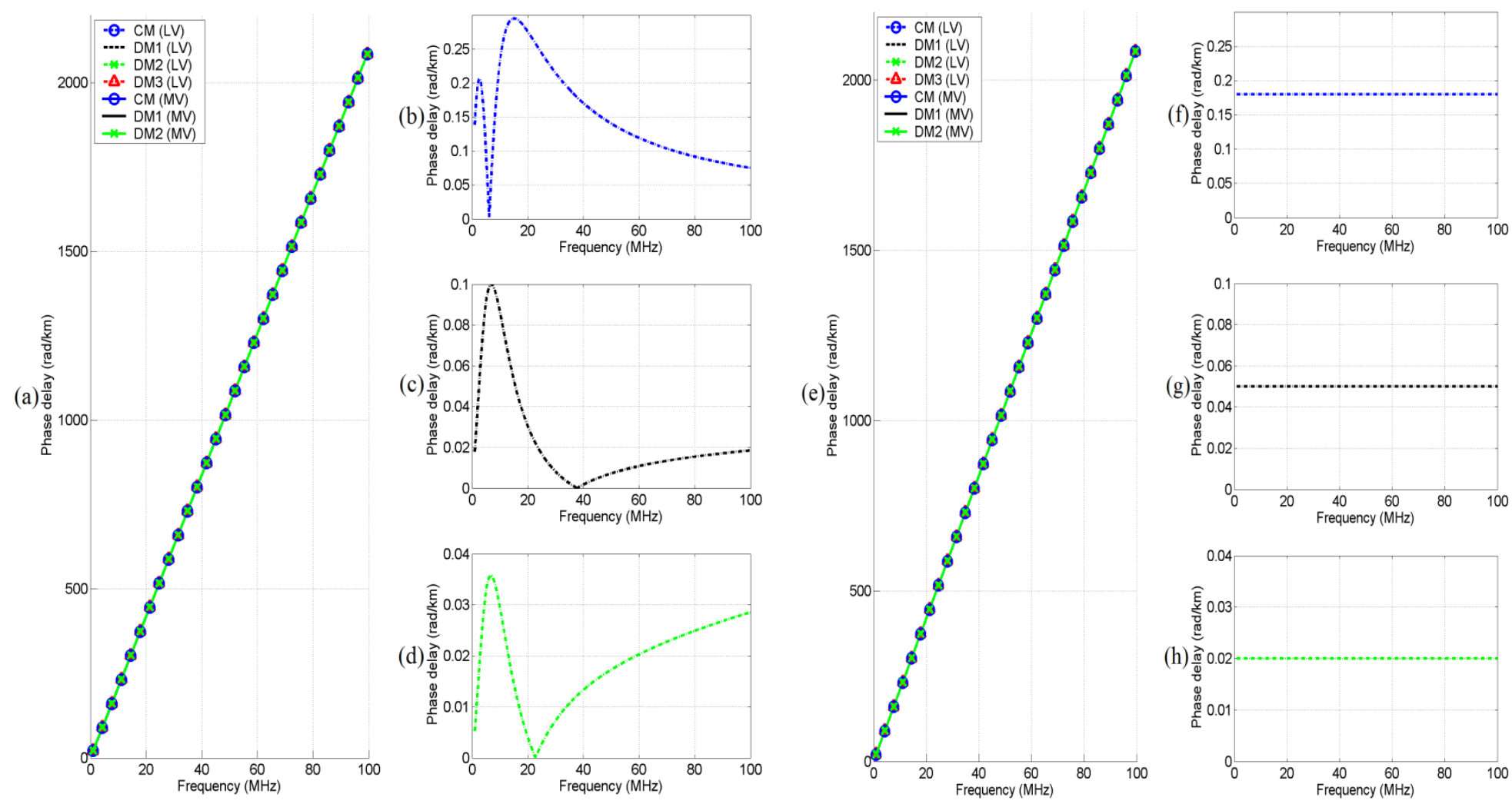

Figure 3. Phase delays of overhead LV/BPL and MV/BPL distribution lines when hybrid and TEP methods are applied (the subchannel frequency spacing is equal to $0.1 \mathrm{MHz}$ ). (a) All the modes -hybrid method-. (b) Absolute difference between $\mathrm{CM}^{\mathrm{LV}}$ and $\mathrm{CM}^{\mathrm{MV}}$-hybrid method-. (c) Absolute difference between $\mathrm{DM}_{1}^{\mathrm{LV}}$ and $\mathrm{DM}_{1}^{\mathrm{MV}}$-hybrid method-. (d) Absolute difference between $\mathrm{DM}_{2}^{\mathrm{LV}}$ and $\mathrm{DM}_{2}^{\mathrm{MV}}$-hybrid method-. (e) All the modes -TEP method-. (b) Absolute difference between $\mathrm{CM}^{\mathrm{LV}}$ and $\mathrm{CM}^{\mathrm{MV}}$-TEP method-. (c) Absolute difference between $\mathrm{DM}_{1}^{\mathrm{LV}}$ and $\mathrm{DM}_{1}^{\mathrm{MV}}$-TEP method-. (d) Absolute difference between $\mathrm{DM}_{2}^{\mathrm{LV}}$ and $\mathrm{DM}_{2}^{\mathrm{MV}}-\mathrm{TEP}$ method-.

As it has already been presented in [1], [2], [4], [19], [21], [30]-[32], the EVD modal voltages $\mathbf{V}^{X V, \mathrm{~m}}(z)=\left[\begin{array}{llll}V_{1}^{X V, \mathrm{~m}}(z) & \cdots & V_{n}^{X V, \mathrm{~m}}(z)\end{array}\right]^{\mathrm{T}}$ and the EVD modal currents $\mathbf{I}^{X V, \mathrm{~m}}(z)=\left[\begin{array}{lll}I_{1}^{X V, \mathrm{~m}}(z) & \cdots & I_{n}^{X V, \mathrm{~m}}(z)\end{array}\right]^{\mathrm{T}}$ may be related to the respective line quantities $\quad \mathbf{V}^{X V}(z)=\left[\begin{array}{llll}V_{1}^{X V}(z) & \cdots & V_{n}^{X V}(z)\end{array}\right]^{\mathrm{T}}$ and $\mathbf{I}^{X V}(z)=\left[\begin{array}{llll}I_{1}^{X V}(z) & \cdots & I_{n}^{X V}(z)\end{array}\right]^{\mathrm{T}}$ via the similarity transformations

$$
\begin{aligned}
& \mathbf{V}^{X V}(z)=\mathbf{T}_{\mathrm{V}}^{X V} \cdot \mathbf{V}^{X V, \mathrm{~m}}(z) \\
& \mathbf{I}^{X V}(z)=\mathbf{T}_{\mathrm{I}}^{X V} \cdot \mathbf{I}^{X V, \mathrm{~m}}(z)
\end{aligned}
$$

where []$^{\mathrm{T}}$ denotes the transpose of a matrix, $\mathbf{T}_{\mathrm{V}}^{X V}$ and $\mathbf{T}_{\mathrm{I}}^{X V}$ are $n^{X V} \times n^{X V}$ matrices depending on the overhead power grid type, the frequency, the physical properties of the conductors and the geometry of the MTL configuration. Through the aforementioned 
equations, the line voltages and currents are expressed as appropriate superpositions of the respective EVD modal quantities. From eq. (1)

$$
\mathbf{V}^{X V, \mathrm{~m}}(0)=\left[\mathbf{T}_{\mathrm{V}}^{X V}\right]^{-1} \cdot \mathbf{V}^{X V}(0)
$$

The TM2 method -based on the scattering matrix theory formalism [2], [3], [5]-[7], [12]-[14], [24], [26], [32], [33], [50] and presented analytically in [3], [5]models the spectral relationship between $V_{i}^{X V, \mathrm{~m}}(z), \quad i=1, \ldots, n^{X V}$ and $V_{i}^{X V, \mathrm{~m}}(0), i=1, \ldots, n^{X V}$ proposing operators $H_{i j}^{X V, \mathrm{~m}}\{\cdot\}, i, j=1, \ldots, n^{X V}$ so that

$$
\mathbf{V}^{X V, \mathrm{~m}}(z)=\mathbf{H}^{X V, \mathrm{~m}}\left\{\mathbf{V}^{X V, \mathrm{~m}}(0)\right\}
$$

where

$$
\mathbf{H}^{X V, \mathrm{~m}}\{\cdot\}=\left[\begin{array}{ccc}
H_{11}^{X V, \mathrm{~m}}\{\cdot\} & \cdots & H_{1 n}^{X V, \mathrm{~m}}\{\cdot\} \\
\vdots & \ddots & \vdots \\
H_{n 1}^{X V, \mathrm{~m}}\{\cdot\} & \cdots & H_{n n}^{X V, \mathrm{~m}}\{\cdot\}
\end{array}\right]
$$

is a $n^{X V} \times n^{X V}$ matrix operator whose elements $H_{i j}^{X V, \mathrm{~m}}\{\cdot\}, i, j=1, \ldots, n^{X V}$ are the EVD modal transfer functions, and $H_{i, j}^{\mathrm{XV}, \mathrm{m}}$ denotes the element of matrix $\mathbf{H}^{\mathrm{XV}, \mathrm{m}}\{\cdot\}$ in row $i$ of column $j$ [2]-[7], [12]-[14], [24], [30]-[33]. Combining eqs. (1) and (5), the $n^{X V} \times n^{X V}$ matrix channel transfer function $\mathbf{H}^{X V}\{\cdot\}$ relating $\mathbf{V}^{X V}(z)$ with $\mathbf{V}^{X V}(0)$ through

is determined from

$$
\mathbf{V}^{X V}(z)=\mathbf{H}^{X V}\left\{\mathbf{V}^{X V}(0)\right\}
$$

$$
\mathbf{H}^{X V}\{\cdot\}=\mathbf{T}_{\mathrm{V}}^{X V} \cdot \mathbf{H}^{X V, \mathrm{~m}}\{\cdot\} \cdot\left[\mathbf{T}_{\mathrm{V}}^{X V}\right]^{-1}
$$

Based on eq. (7), the $n^{X V} \times n^{X V}$ matrix transfer functions $\mathbf{H}^{X V}\{\cdot\}$ of the overhead BPL distribution networks are determined [2]-[7], [12]-[14], [24], [30]-[33].

As it has already been mentioned in [3], [5], TM2 method is extremely resultful since it is able to calculate EVD modal transfer functions associated with complex networks including various types of overhead BPL configurations, any type of interconnection at the branches and any type of branch termination. In contrast with its ancestor methods, TM2 method does not consider specific transmission assumptions that reduce the generality of the method [2], [3], [5]-[8], [12]-[14], [24], [26], [32], [33], [50]-[52]. Moreover, applying TM2 method, the problem of mode mixture is fully investigated through the definition of the EVD matrix channel transfer function -as given in eq. (7)-. Also, TM2 method is a pure microwave engineering technique that can be easily detailed to ECE students during the course of Microwave Engineering.

With reference to eq. (7), $\mathbf{T}_{\mathrm{v}}^{X V}$ is $n^{X V} \times n^{X V}$ matrix that describes the power allocation of each modal transfer function to the transfer functions of the line quantities. Similarly to [1], [63], in order to completely bypass the application of the bottom-up approach of the hybrid method and to simplify the following analysis to ECE students, TEP method argues that the real parts of the elements of matrix $\mathbf{T}_{\mathrm{V}}^{X V}$ can be replaced by their mean values while their imaginary parts can be assumed equal to 0 in the BPL operation frequency range. For the sake of clarity and terseness, these figures are omitted in this companion paper since they resemble to Figs. 3(a)-(j) of [1]. Anyway, since the main interest of this paper is concentrated on the behavior of modal channels as described in eqs. (4) and (5), the further examination of matrix $\mathbf{T}_{\mathrm{V}}^{X V}$ is omitted. 
With reference to eqs. (4) and (5), the $n^{X V} \times n^{X V}$ matrix transfer functions $\mathbf{H}^{X V, m}\{\cdot\}$ of the overhead BPL distribution networks can be determined combining the set of linear simplifications of TEP method, concerning modal attenuation coefficients and modal phase delays, and TM2 method without using the complicated bottom-up approach of the hybrid method.

\section{Numerical Results and Discussion}

First of all, the numerical results of this Section focus on identifying the TEP method as an efficient pedagogical tool that can be comfortably presented to ECE students during the courses of Microwave and Circuit/System Engineering of their ECE program. TEP method succeeds in providing the general concept of designing overhead BPL networks without deviating from the "real world" conditions and confusing ECE students. In addition, except for the pedagogical purposes of TEP method, the simulations of various types of overhead LV/BPL and MV/BPL transmission channels aim at revealing to ECE students: (a) their broadband transmission characteristics; (b) how their spectral behavior is affected by several factors, such as the type/topology of the overhead power grid and the multiplicity of branches; (c) the introduction of appropriate simplified approximations; and (d) the common PHY handling perspective among different types of BPL distribution power grids.

Conversely to [1], this paper mainly focuses on the modal behavior and the modal transmission characteristics of overhead LV/BPL and MV/BPL networks. As mentioned in Section III, since the modes supported by the overhead LV/BPL and MV/BPL configurations may be examined separately, it is assumed for simplicity that the BPL signal is injected directly into the modes [2]-[7], [12]-[14], [19]-[25], [30]-[33]; thus, the complicated EVD modal analysis of [21], briefly described in Section III, is avoided to be presented in ECE students. Hence, after the presentation of linear simplifications of TEP method, which concern bottom-up approach, that are available $a b$ initio for given overhead LV and MV MTL configuration and TM2 method, concerning the integration of TEP method, ECE students directly enter into the findings of this Section.

For the following numerical computations, the three-phase four-conductor overhead LV and the three-phase three-conductor overhead MV distribution line configurations depicted in Figs. 1(a) and 1(b), respectively, have been considered.

The following discussion will focus on the transmission characteristics related to the $\mathrm{CM}^{X V}$ and to the $\mathrm{DM}^{X V}$ s of the overhead BPL systems, as well. Since, as mentioned in Section III, the DMs of the same overhead power grid type exhibit an almost identical spectral behavior, the transmission characteristics of only one DM of each overhead power grid type, say that of $\mathrm{DM}_{1}^{\mathrm{LV}}$ and $\mathrm{DM}_{1}^{\mathrm{MV}}$, will be examined, hereafter.

The simple overhead topology of Fig. 4(a) of [1], having $N$ branches has been considered. With reference to Fig. 4(a) of [1], the transmitting and the receiving ends are assumed matched to the characteristic impedance of the mode considered, whereas the branch terminations are assumed open circuit [2]-[7], [24], [27], [30]-[33], [64]. Also, five indicative overhead topologies, which are common for both overhead LV/BPL and MV/BPL systems, concerning end-to-end connections of average lengths equal to $1000 \mathrm{~m}$ are examined [3], [5]-[7], [17]-[19], [22], [24], [25], [27], [28], [33], [34], [37], [43], [53]-[55]. Their topological characteristics are reported in Table I. 
A. End-to-End Channel Attenuation - Comparison of the TEP Method with the Hybrid Method - Comparison between Overhead LV/BPL and MV/BPL Topologies

As it concerns the hybrid method, in Figs. 4(a) and 4(d), the end-to-end channel attenuation from $\mathrm{A}$ to $\mathrm{B}$ is plotted with respect to frequency for the aforementioned five indicative topologies for the propagation of $\mathrm{CM}^{\mathrm{LV}}$ and $\mathrm{DM}_{1}^{\mathrm{LV}}$, respectively. In Figs. 4(b) and 4(e), similar plots are given for the propagation of $\mathrm{CM}^{\mathrm{MV}}$ and $\mathrm{DM}_{1}^{\mathrm{MV}}$, respectively. In Figs. 4(c), 4(f), 4(g), and 4(h), the absolute difference of the end-to-end channel attenuations from $\mathrm{A}$ to $\mathrm{B}$ is also drawn versus frequency for the aforementioned indicative topologies in the cases of: (i) $\mathrm{CM}^{\mathrm{LV}}$ and $\mathrm{CM}^{\mathrm{MV}}$; (ii) $\mathrm{DM}_{1}^{\mathrm{LV}}$ and $\mathrm{DM}_{1}^{\mathrm{MV}}$; (iii) $\mathrm{CM}^{\mathrm{LV}}$ and $\mathrm{DM}_{1}^{\mathrm{LV}}$; and (iv) $\mathrm{CM}^{\mathrm{MV}}$ and $\mathrm{DM}_{1}^{\mathrm{MV}}$; respectively. In Figs. 5(a)-(h), same plots are given in the case of the TEP method.

From Figs. 4(a)-(h) and 5(a)-(h), several interesting remarks can be pointed out regarding the convergence of TEP and hybrid method as well as the transmission characteristics of overhead LV/BPL and MV/BPL networks:

- In all the cases examined, TEP method efficiently approximates the hybrid method. As it has already been identified in [2]-[7], [12]-[14], [18], [24], [29]-[33], [51], [53], [54], [56], overhead BPL networks are mainly affected by the multipath environment rather than "LOS" attenuation. Actually, these notches are superimposed on the exponential "LOS" attenuation of each mode. Since TM2 method is responsible for dealing with overhead BPL topologies, the TEP and hybrid methods present similarities either in the positions of spectral notches or in the extent of these notches despite the fact that different bottom-up approaches are assumed.

- Since the dominant factor that affect signal propagation in overhead LV/BPL and MV/BPL channels is the superimposed multipath, an indicative picture of the transmission characteristics of the modes can be obtained studying the transmission characteristics of only one mode of each power grid type. This is a rather typical procedure in BPL analysis [2]-[7], [12], [14], [24], [27], [32], [33], [54].

- Regardless of the method considered, the spectral behavior of end-to-end channel attenuation of modes depends drastically on the frequency, the mode considered, the physical properties of the conductors used, the end-to-end -"LOS"- distance and the number and the electrical length of the branches encountered along the end-to-end transmission path. This is a critical point of the analysis that should be highlighted to ECE students.

- Already mentioned in [3]-[7], [12]-[14], [24], [30], [31], [33], [57], there are three major channel classes for LV/BPL and MV/BPL channels: (i) "LOS" channels, when no branches are encountered and, consequently, no spectral notches are observed; (ii) Good channels, when the number of branches is small and their electrical length is large. Shallow spectral notches are observed. Suburban case will represent good channel class, hereafter; and (iii) Bad channels, when the number of branches is large and their electrical length is small. Deep spectral notches are observed. Urban case B will represent bad channel class, hereafter. 
Table I. Five Indicative Overhead Topologies [3], [4], [8], [24].

\begin{tabular}{|c|c|c|c|c|}
\hline Denotation & Description & $\begin{array}{l}\text { Number } \\
\text { of } \\
\text { Branches } \\
(N)\end{array}$ & $\begin{array}{l}\text { Lengths } \\
\text { Distribution TLs } \\
{\left[L_{1} \ldots L_{\mathrm{N}+1}\right]} \\
\end{array}$ & $\begin{array}{l}\text { Lengths of Branch TLs } \\
{\left[\begin{array}{llll}L_{\mathrm{b} 1} & \ldots & \left.L_{\mathrm{b} N}\right]\end{array}\right.}\end{array}$ \\
\hline $\begin{array}{l}\text { Urban case } \\
\text { A }\end{array}$ & $\begin{array}{l}\text { A typical urban } \\
\text { topology }\end{array}$ & 3 & $\begin{array}{lll}500 \mathrm{~m} & 200 \mathrm{~m} & 100 \mathrm{~m} \\
200 \mathrm{~m}] & & \end{array}$ & {$[8 \mathrm{~m} \mathrm{13m} \mathrm{10m]}$} \\
\hline $\begin{array}{l}\text { Urban case } \\
\text { B }\end{array}$ & $\begin{array}{l}\text { An aggravated } \\
\text { urban topology }\end{array}$ & 5 & $\begin{array}{l}{[200 \mathrm{~m} \quad 50 \mathrm{~m} \quad 100 \mathrm{~m}} \\
200 \mathrm{~m} 300 \mathrm{~m} \quad 150 \mathrm{~m}]\end{array}$ & $\begin{array}{llll}{[12 \mathrm{~m}} & 5 \mathrm{~m} & 28 \mathrm{~m} & 41 \mathrm{~m} \\
17 \mathrm{~m}] & & & \\
\end{array}$ \\
\hline $\begin{array}{l}\text { Suburban } \\
\text { case }\end{array}$ & $\begin{array}{l}\text { A typical } \\
\text { suburban } \\
\text { topology }\end{array}$ & 2 & {$[500 \mathrm{~m} 400 \mathrm{~m} 100 \mathrm{~m}]$} & {$[50 \mathrm{~m} 10 \mathrm{~m}]$} \\
\hline Rural case & $\begin{array}{l}\text { A typical rural } \\
\text { topology }\end{array}$ & 1 & {$[600 \mathrm{~m} 400 \mathrm{~m}]$} & {$[300 \mathrm{~m}]$} \\
\hline $\begin{array}{l}\text { "LOS" } \\
\text { case*" }\end{array}$ & $\begin{array}{l}\text { "LOS" } \\
\text { transmission }\end{array}$ & 0 & {$[1000 \mathrm{~m}]$} & - \\
\hline
\end{tabular}

(*: "LOS" topology corresponds to Line of Sight transmission in wireless channels)

- Regardless of the considered method, the channel attenuation differences between same modes of overhead LV/BPL and MV/BPL networks remain limited. This is due to the fact that the different modal transmission performances of overhead LV/BPL and MV/BPL channels are only marginally influenced by different wire positioning in the longitudinal cross-section of the line. Actually, this is an evidence for their common PHY handling that is further analyzed in the following subsections.

- MTL theory and EVD modal analysis are definitely useful tools to face the problem. Nevertheless, it is mandatory to consider that modal transmission characteristics of overhead LV/BPL and MV/BPL channels are strongly influenced by load characteristics, on the one hand, and by modem connection, on the other [64]. Since this analysis is mainly focused on ECE students, the assumption of optimal data transmission is acceptable; say, each mode $\left(\mathrm{CM}^{\mathrm{XV}}\right.$ and $\mathrm{DM}^{\mathrm{XV}} \mathrm{s}$ ) can propagate along a fictitious two-conductor transmission line with matched terminations.

On the basis of the previous findings and as it concerns the modal transmission characteristics, only one mode of each overhead power grid type is going to be examined; say that of $\mathrm{DM}_{1}^{\mathrm{LV}}$ and $\mathrm{DM}_{1}^{\mathrm{MV}}$. As it regards the topological features, "LOS" transmission case, good channel case and bad channel case are going to be representative cases for the rest of this paper. 


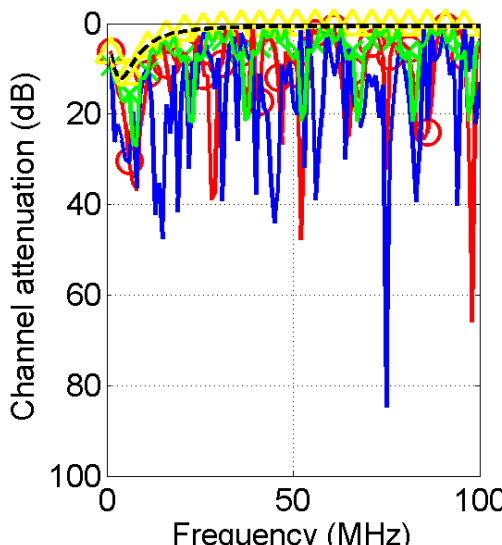

(a)

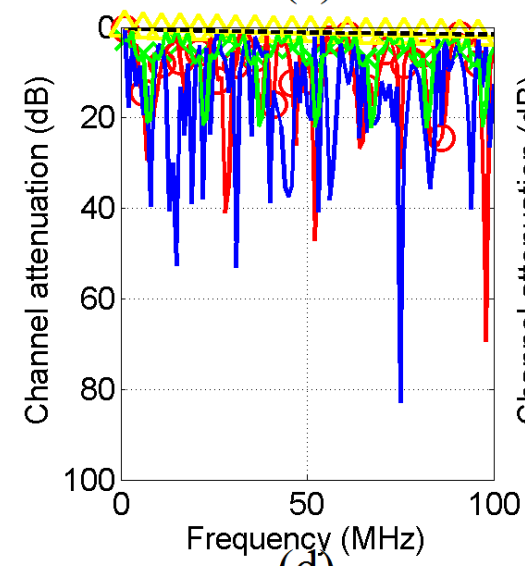

d)

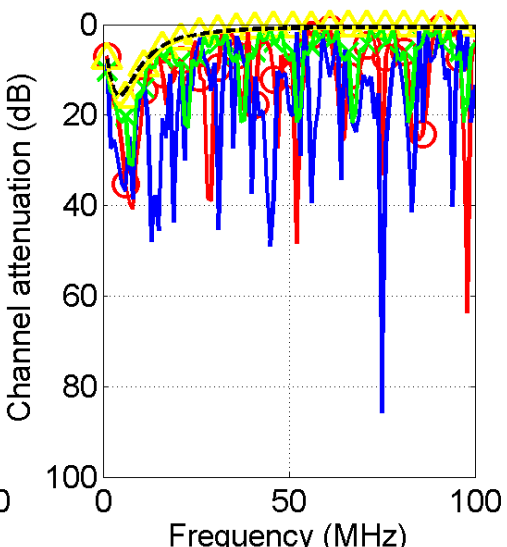

(b)

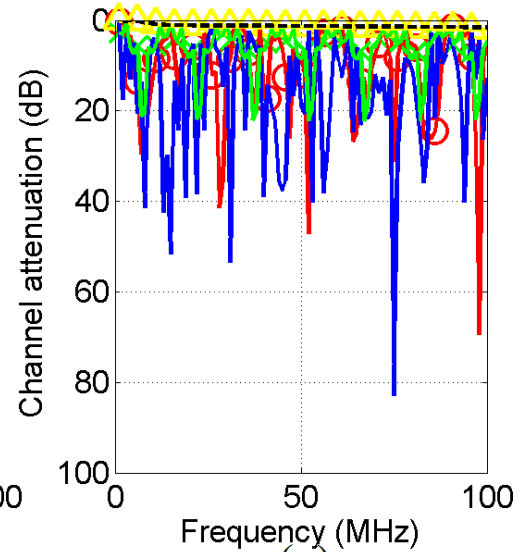

(e)

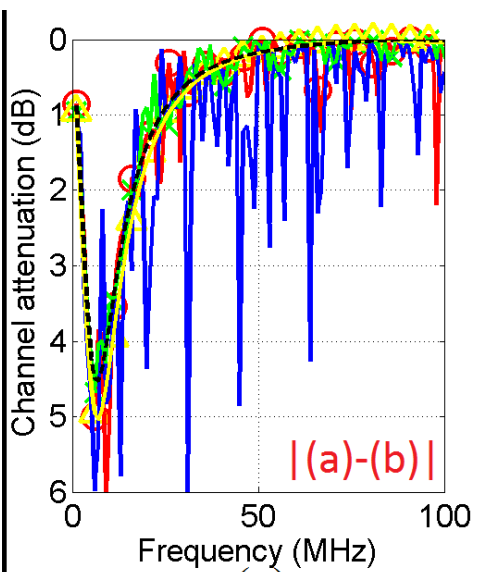

(c)

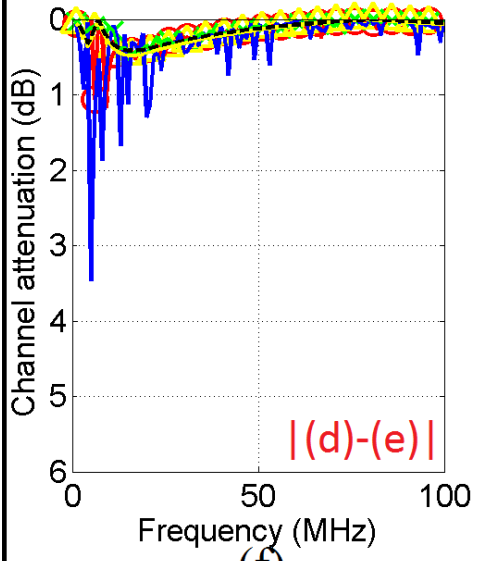

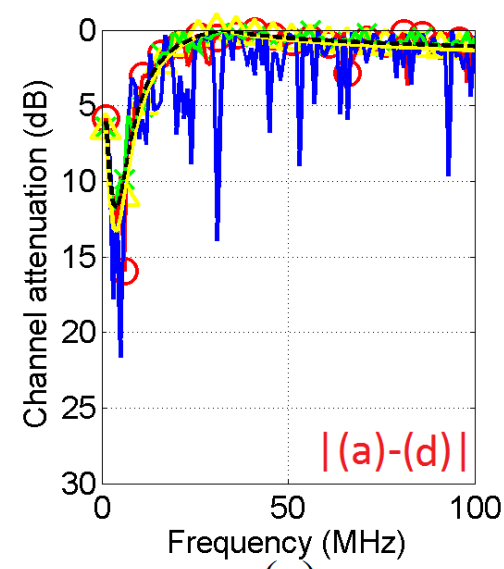

$(\mathrm{g})$

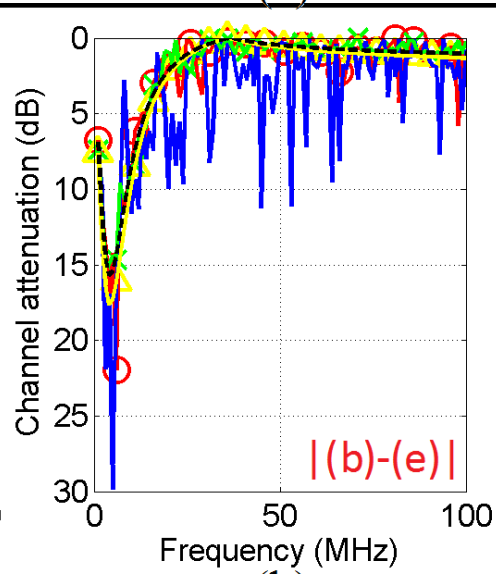

(h)

Figure 4. End-to-end channel attenuation versus frequency for urban case $A(\theta)$, urban case B $(-)$, suburban case $(-\star)$, rural case $(-)$, and "LOS" transmission case (----) when the hybrid method is adopted (the subchannel frequency spacing is equal to $1 \mathrm{MHz}$ ).
(a) $\mathrm{CM}^{\mathrm{LV}}$. (b) $\mathrm{CM}^{\mathrm{MV}}$. (c) Absolute difference between $\mathrm{CM}^{\mathrm{LV}}$ and $\mathrm{CM}^{\mathrm{MV}}$.

(d) $\mathrm{DM}_{1}^{\mathrm{LV}}$. (e) $\mathrm{DM}_{1}^{\mathrm{MV}}$. (f) Absolute difference between $\mathrm{DM}_{1}^{\mathrm{LV}}$ and $\mathrm{DM}_{1}^{\mathrm{MV}}$.

(g) Absolute difference between $\mathrm{CM}^{\mathrm{LV}}$ and $\mathrm{DM}_{1}^{\mathrm{LV}}$. (h) Absolute difference between $\mathrm{CM}^{\mathrm{MV}}$ and $\mathrm{DM}_{1}^{\mathrm{MV}}$. 


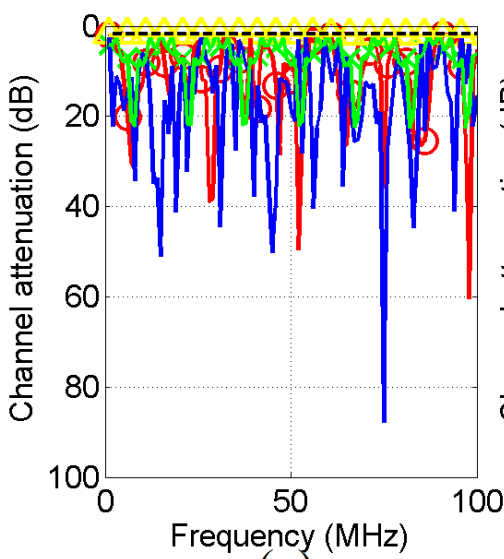

(a)
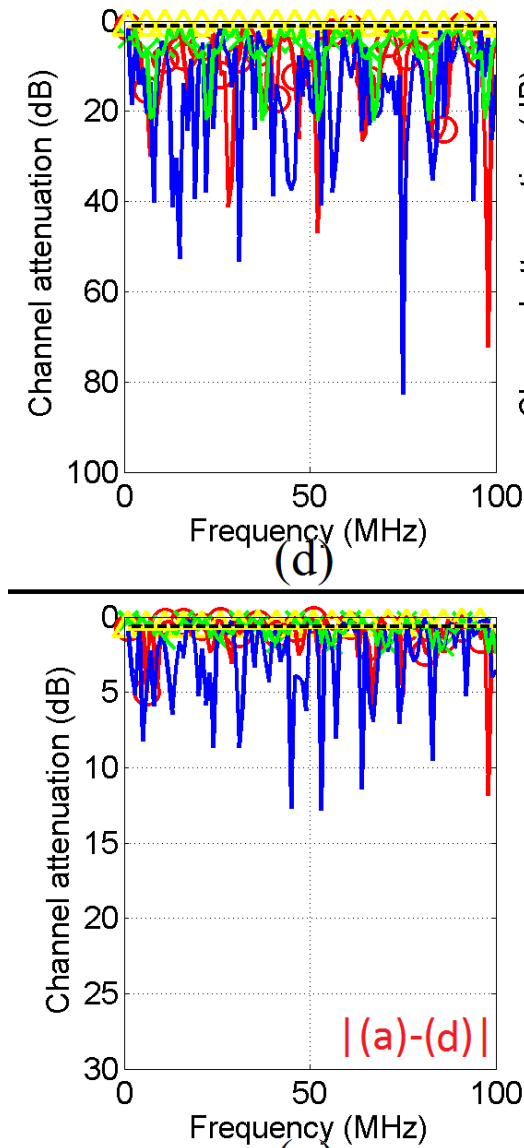

(g)

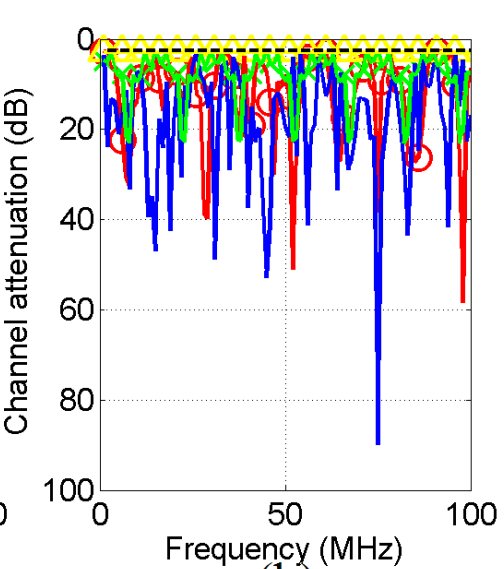

(b)

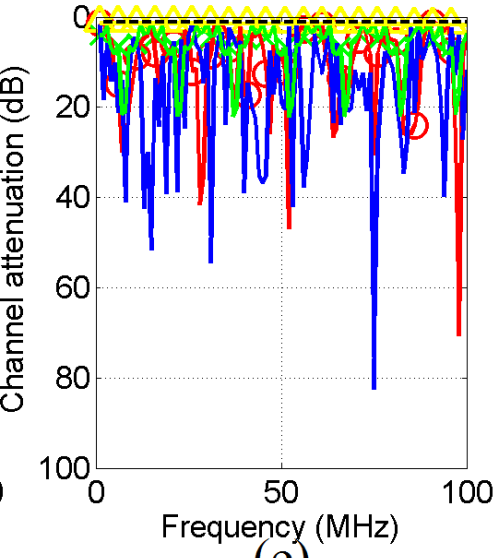

(e)

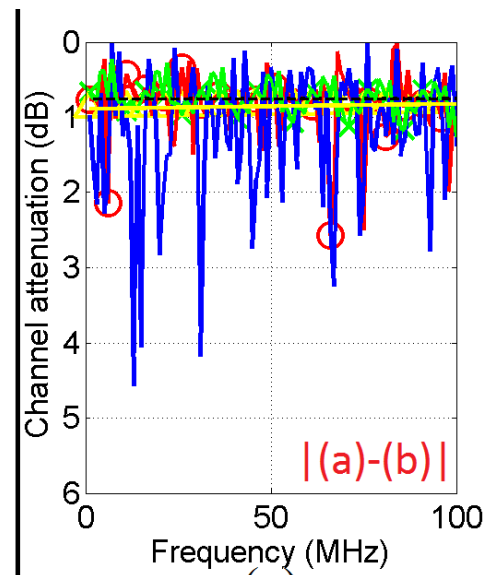

(c)

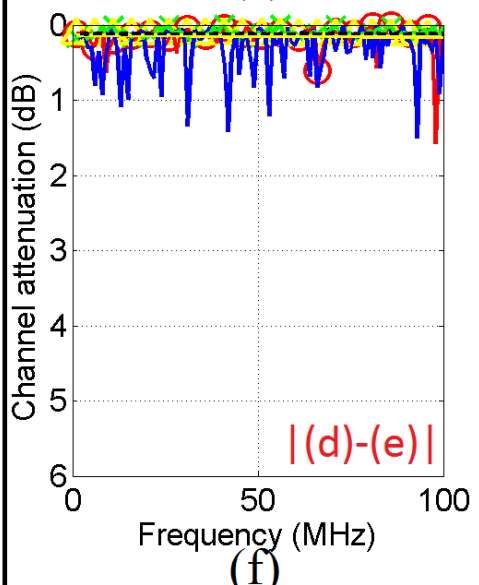

(f)

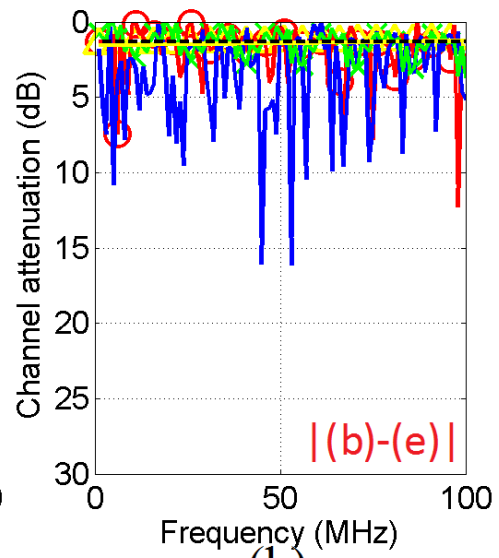

(h)

Figure 5. Same plots with Fig. 4 but for the TEP method.

B. The Effect of Branch Length - Introduction of Simplified Approach with Two-Way Power Dividers - Comparison between Overhead LV/BPL and MV/BPL Topologies

As it has already been identified in [2], [12], [14], [32], apart from causing spectral notches, the various branches also cause additional stepwise discontinuities to the channel attenuation at each branch encountered along the end-to-end transmission path. 
The effect of the branch length on the attenuation discontinuity at each branch is examined in Figs 6(a) and 6(d), where the channel attenuation of $\mathrm{DM}_{1}^{\mathrm{LV}}$ is plotted versus the distance from the transmitting end -see Fig. 4(a) of [1], point A- for good channel class case, Topology 1 -see Table II-, bad channel class case, Topology 2 -see Table II-, and the "LOS" transmission case at $\mathrm{f}=25 \mathrm{MHz}$ and $\mathrm{f}=76 \mathrm{MHz}$, respectively. In Figs. 6(b) and 6(e), similar plots are given for the propagation of $\mathrm{DM}_{1}^{\mathrm{MV}}$. In Figs. 6(c) and 6(f), the absolute difference of the channel attenuations between $\mathrm{DM}_{1}^{\mathrm{LV}}$ and $\mathrm{DM}_{1}^{\mathrm{MV}}$ is also drawn with respect to the distance from the transmitting end for the same topologies at $\mathrm{f}=25 \mathrm{MHz}$ and $\mathrm{f}=76 \mathrm{MHz}$, respectively. Note that in Figs. 6(a)-(f), hybrid method is applied whereas in Figs. 7(a)-(f), same plots are given when TEP method is applied.

Comparing Figs. 6(a)-(f) with 7(a)-(f), the channel attenuation discontinuity results of TEP method are very close to respective ones of the hybrid method. This is due to the fact that multipath aggravation is described in both methods by the TM2 method. In addition, ECE students can easily understand that the attenuation discontinuity at each branch primarily depends on the frequency and on its electrical length rather than overhead distribution power grid type. Actually, from Figs. 6(c), 6(f), 7(c) and 7(f), it is demonstrated that the attenuation differences between overhead LV/BPL and $\mathrm{MV} / \mathrm{BPL}$ channels are lower than $0.5 \mathrm{~dB}$ in the majority of the cases for a given overhead power grid topology.

Moreover, observing Figs. 6(a)-(e) and 7(a)-(e), it is noticed that as the branches become longer, the spectral behavior of the BPL networks tends to converge to the spectral behavior of the respective BPL networks with branch terminations matched to the characteristic impedance of the mode examined; say approximately a two-way power divider or 3.01dB superimposed attenuation per each single branch [18], [29], [35], [51], [53], [55], [58]-[60]. This result defines the first interesting circuital approximation of TEP method and, at the same time, it is easily understandable by ECE students since power dividers are essential part of the material of their Microwave Engineering and Circuit/System Engineering courses.

Finally, from Figs. 4(a)-(h), 5(a)-(h), 6(a)-(f) and 7(a)-(f), it is obvious that TEP method provides accurate results in comparison with the respective ones of the hybrid method. Therefore, only TEP method is considered for the rest of this paper.

\section{Multiple Branches at given Junction - Comparison between Overhead LV/BPL and MV/BPL Topologies}

A typical urban overhead LV topology can serve 10-60 household customers while a typical urban overhead MV topology may support 2-8 MV/LV transformers. These typical overhead topologies are mainly of radial configuration either with a single branch or with multiple branches at the same junction [18], [19], [22], [27], [28], [53]-[55], [57]-[60].

To demonstrate the effect of multiple branches at given junction on the channel attenuation, the end-to-end channel attenuation of $\mathrm{DM}_{1}^{\mathrm{LV}}$ from $\mathrm{A}$ to $\mathrm{B}$ is plotted versus frequency for good channel class case, Topology 3 -see Table III-, bad channel class case, Topology 4 -see Table III-, and "LOS" transmission case in Fig. 8(a). In Fig. 8(b), similar plots are given for the propagation of $\mathrm{DM}_{1}^{\mathrm{MV}}$. In Fig. 8(c), the absolute difference 
of the channel attenuations between $\mathrm{DM}_{1}^{\mathrm{LV}}$ and $\mathrm{DM}_{1}^{\mathrm{MV}}$ is also drawn with respect to frequency for the same topologies.

Table II. Two Indicative Overhead Topologies with Longer Branches

\begin{tabular}{|c|c|c|c|c|}
\hline Denotation & Description & $\begin{array}{l}\text { Times of } \\
\text { longer } \\
\text { branches }\end{array}$ & $\begin{array}{ll}\text { Lengths } & \text { of } \\
\text { Distribution TLs } & \\
{\left[L_{1} \ldots L_{N+1}\right]} & \\
\end{array}$ & $\begin{array}{llll}\text { Lengths of } & \text { Branch } \\
\text { TLs } & & \\
{\left[L_{\mathrm{b} 1} \ldots\right.} & \left.L_{\mathrm{b} N}\right] & \\
\end{array}$ \\
\hline Topology 1 & $\begin{array}{l}\text { Same as good } \\
\text { channel class } \\
\text { case but with } \\
\text { twenty times } \\
\text { longer branches }\end{array}$ & 20 & {$[500 \mathrm{~m} 400 \mathrm{~m} 100 \mathrm{~m}]$} & {$[1000 \mathrm{~m} \mathrm{200m}]$} \\
\hline Topology 2 & $\begin{array}{l}\text { Same as bad } \\
\text { channel class } \\
\text { case but with } \\
\text { twenty times } \\
\text { longer branches }\end{array}$ & 20 & $\begin{array}{l}{[200 \mathrm{~m} \quad 50 \mathrm{~m} \quad 100 \mathrm{~m}} \\
200 \mathrm{~m} 300 \mathrm{~m} \quad 150 \mathrm{~m}]\end{array}$ & $\begin{array}{l}{[240 \mathrm{~m} \quad 100 \mathrm{~m} \quad 560 \mathrm{~m}} \\
820 \mathrm{~m} 340 \mathrm{~m}]\end{array}$ \\
\hline
\end{tabular}

D. Multiple Branch Attenuation Discontinuity and the Extension of Simplified Approach with Two-Way Power Dividers - Comparison between Overhead LV/BPL and MV/BPL Topologies

From Figs. 8(a)-(c), it is evident that the multiple branches at each junction cause additional stepwise attenuation to the stepwise attenuation that already exists due to the single branches. In order to examine the effect of the multiple branches on the attenuation discontinuity at the each junction and the newly proposed simplified approximation method of cascaded two-way power dividers, in Figs 9(a) and 9(d), the channel attenuation of $\mathrm{DM}_{1}^{\mathrm{LV}}$ is plotted versus the distance from the transmitting end 


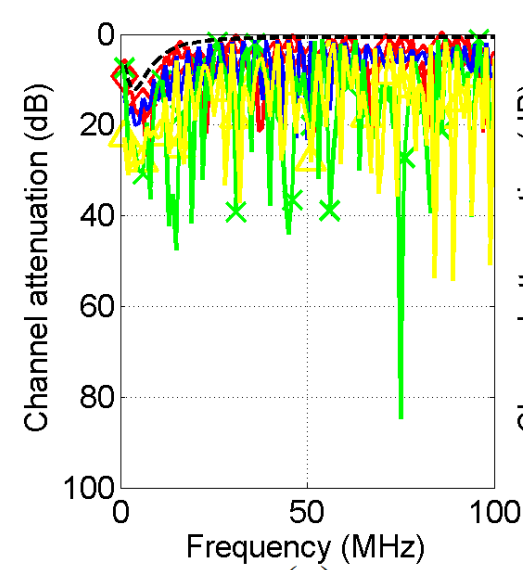

(a)

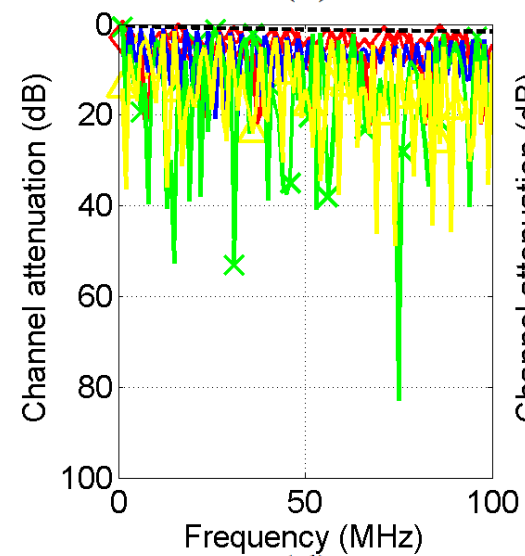

(d)

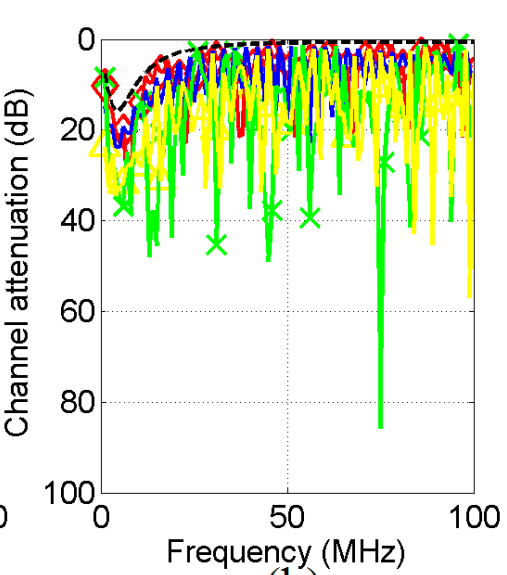

(b)

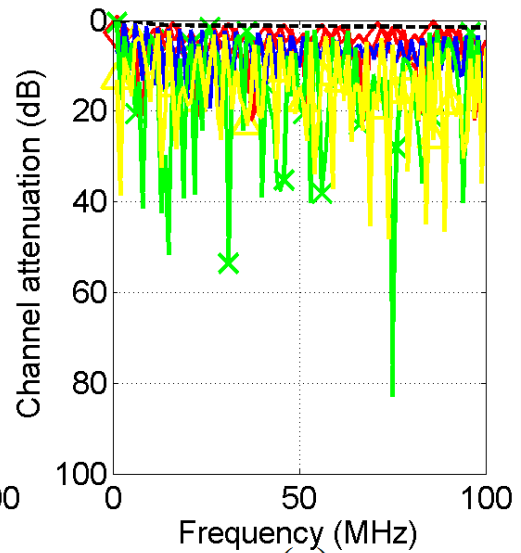

(e)

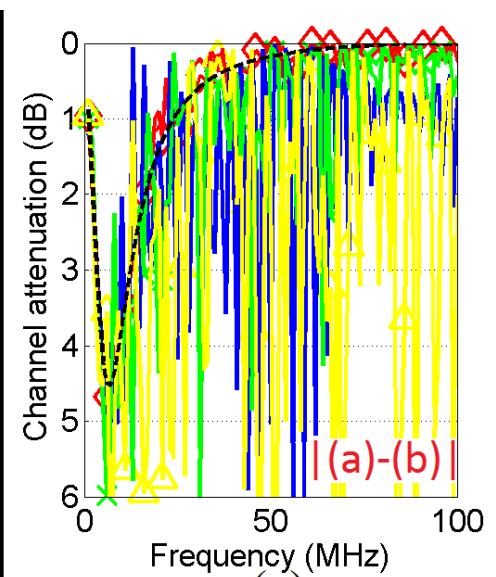

(c)

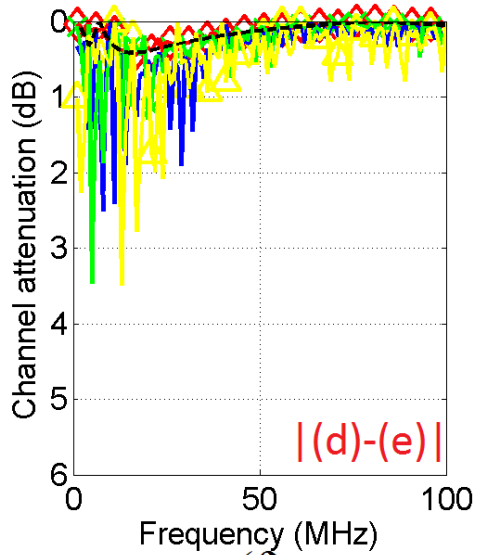

(f)

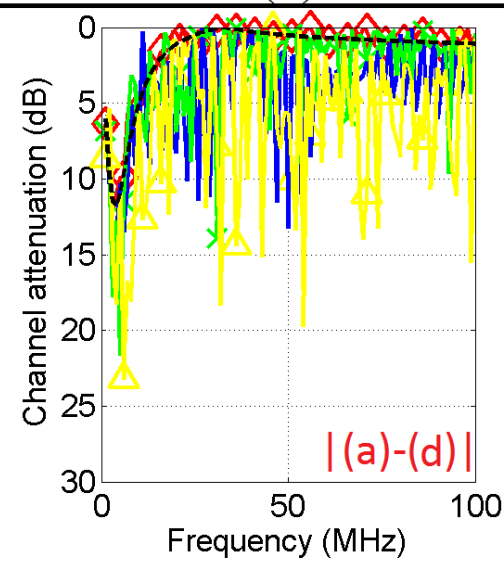

(g)

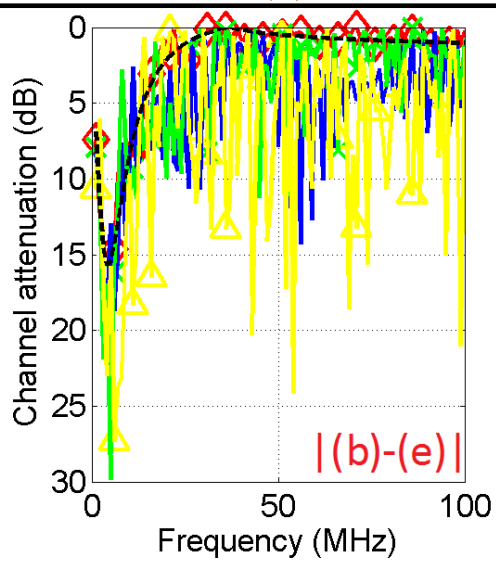

(h)

Figure 6. Channel attenuation versus the distance from the transmitting end (see Fig. 4, point A) for good channel class case $(\star \bullet)$, Topology $1\left(\vartheta^{-}\right)$, bad channel class case ( - ), Topology 2 ( $\square)$, and "LOS" transmission case ( --- ) when hybrid method is adopted (the distance span is equal to $1 \mathrm{~m}$ ). (a) $\mathrm{DM}_{1}^{\mathrm{LV}}$ at $\mathrm{f}=25 \mathrm{MHz}$. (b) $\mathrm{DM}_{1}^{\mathrm{MV}}$ at $\mathrm{f}=25 \mathrm{MHz}$. (c) Absolute difference between $\mathrm{DM}_{1}^{\mathrm{LV}}$ and $\mathrm{DM}_{1}^{\mathrm{MV}}$ at $\mathrm{f}=25 \mathrm{MHz}$. (d) $\mathrm{DM}_{1}^{\mathrm{LV}}$ at $\mathrm{f}=76 \mathrm{MHz}$. (e) $\mathrm{DM}_{1}^{\mathrm{MV}}$ at $\mathrm{f}=76 \mathrm{MHz}$. (e) Absolute difference between $\mathrm{DM}_{1}^{\mathrm{LV}}$ and $\mathrm{DM}_{1}^{\mathrm{MV}}$ at $\mathrm{f}=76 \mathrm{MHz}$. 


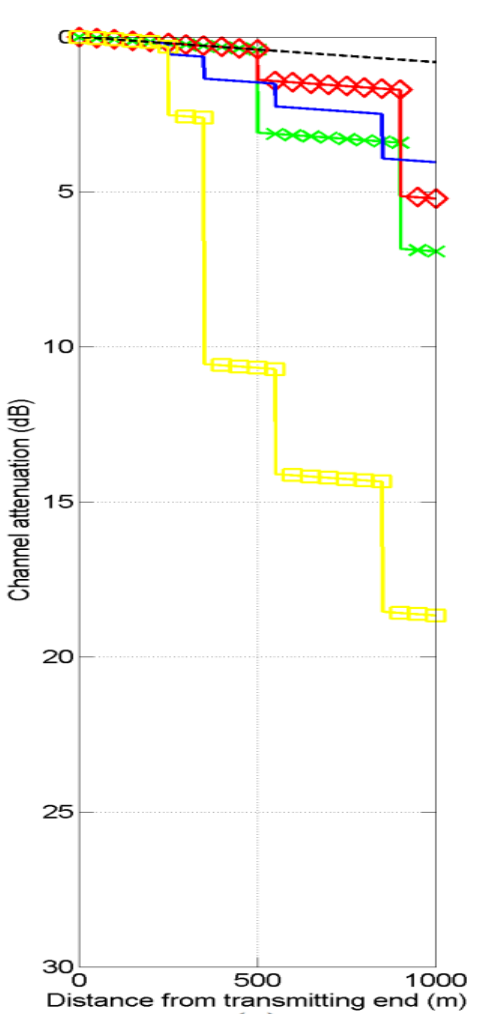

(a)

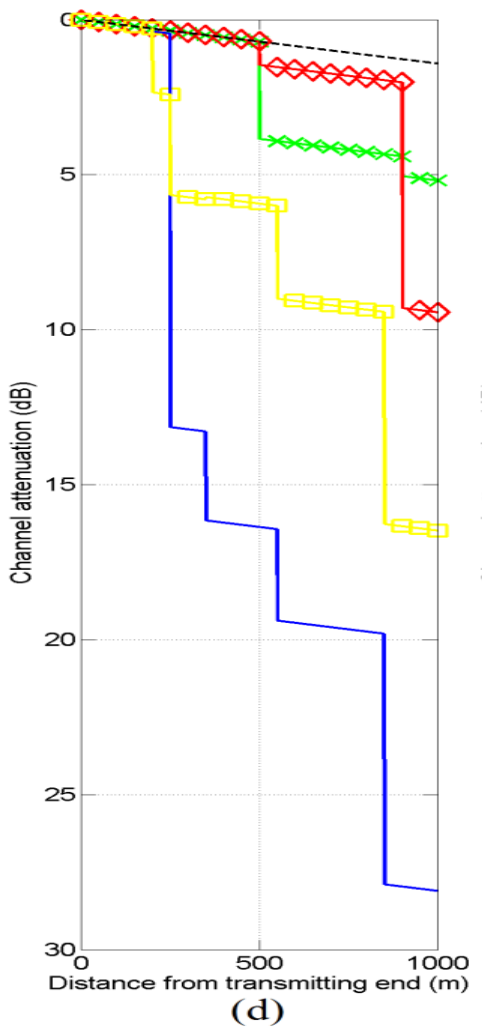

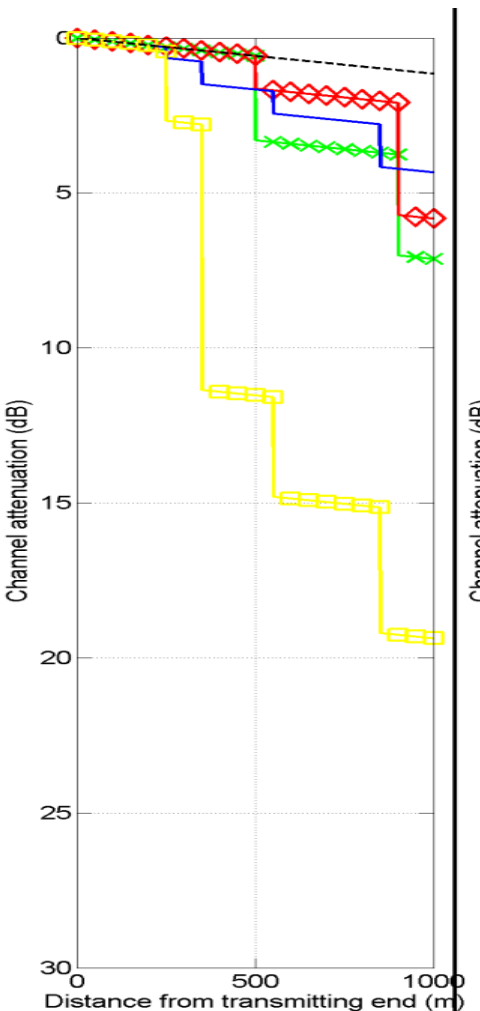

(b)

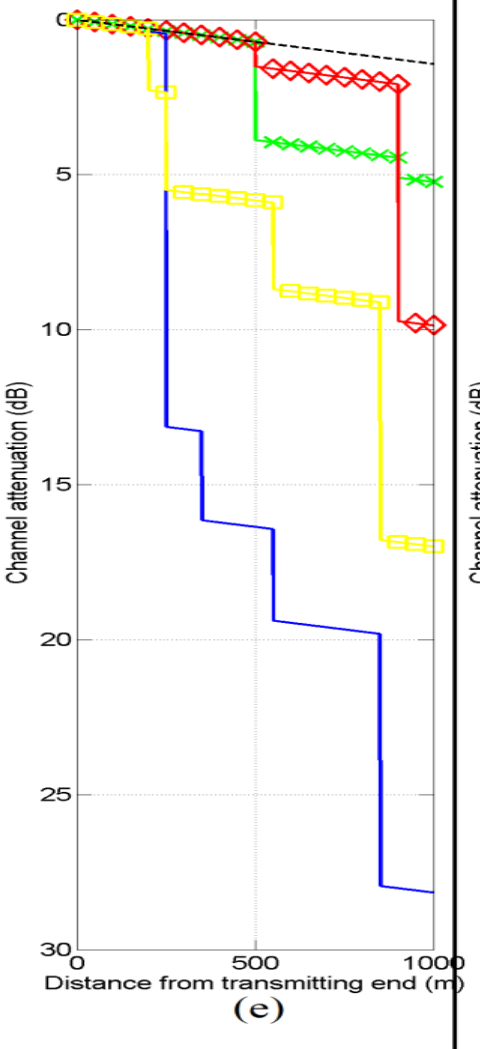

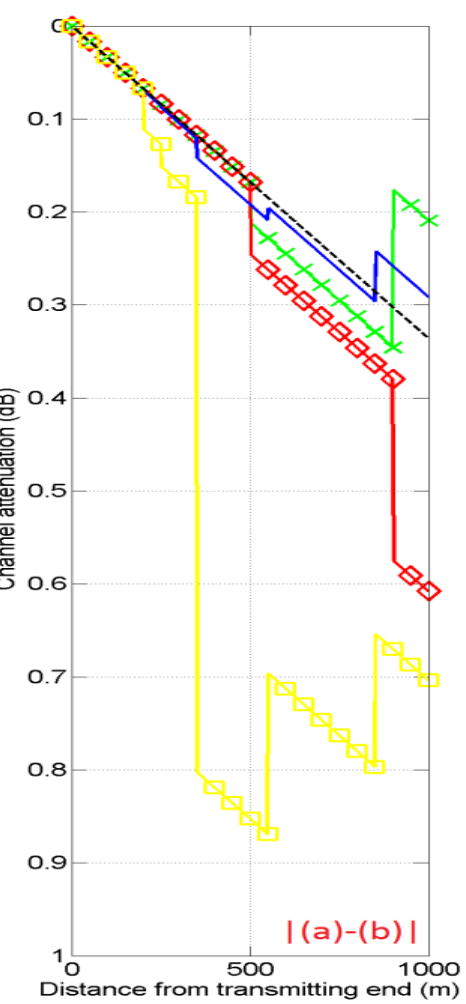

(c)

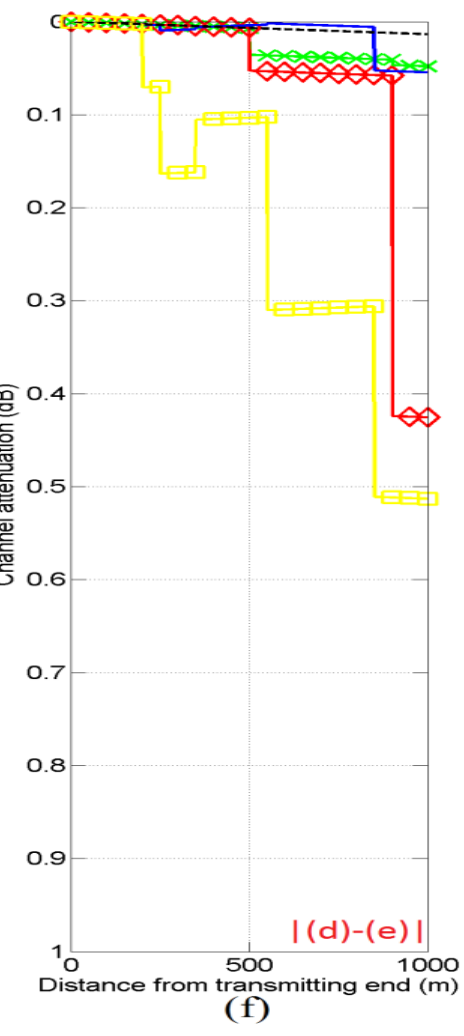

Figure 7. Same plots with Fig. 6 but for the TEP method. 
TABLE III. Two Indicative Overhead Topologies with Multiple Branches at the same Junction.

\begin{tabular}{|c|c|c|c|c|}
\hline Denotation & Description & $\begin{array}{l}\text { Number } \\
\text { of } \\
\text { Multiple } \\
\text { Branches } \\
\text { at the } \\
\text { same } \\
\text { Junction }\end{array}$ & $\begin{array}{l}\text { Lengths } \\
\text { Distribution TLs } \\
{\left[\begin{array}{lll}L_{1} \ldots L_{\mathrm{N}+1} & \text { of }\end{array}\right.}\end{array}$ & $\begin{array}{l}\text { Lengths of Branch } \\
\text { TLs } \\
{\left[\begin{array}{lll}L_{\mathrm{b} 1} & \left.\ldots L_{\mathrm{b} N}\right]\end{array}\right.}\end{array}$ \\
\hline Topology 3 & $\begin{array}{l}\text { Same as good } \\
\text { channel class } \\
\text { case but with } \\
\text { five times } \\
\text { more, same } \\
\text { branches at } \\
\text { each junction }\end{array}$ & 5 & $\begin{array}{l}{[500 \mathrm{~m} 0 \mathrm{~m} 0 \mathrm{~m} 0 \mathrm{~m} 0 \mathrm{~m}} \\
400 \mathrm{~m} 0 \mathrm{~m} 0 \mathrm{~m} 0 \mathrm{~m} 0 \mathrm{~m} \\
100 \mathrm{~m}]\end{array}$ & $\begin{array}{l}{[50 \mathrm{~m} \quad 50 \mathrm{~m} \quad 50 \mathrm{~m} \quad 50 \mathrm{~m}} \\
50 \mathrm{~m} \quad 10 \mathrm{~m} \quad 10 \mathrm{~m} \quad 10 \mathrm{~m} \\
10 \mathrm{~m} 10 \mathrm{~m}]\end{array}$ \\
\hline Topology 4 & $\begin{array}{l}\text { Same as bad } \\
\text { channel class } \\
\text { case but with } \\
\text { five times } \\
\text { more, same } \\
\text { branches at } \\
\text { each junction }\end{array}$ & 5 & $\begin{array}{l}\begin{array}{llllll}200 \mathrm{~m} & 0 \mathrm{~m} & 0 \mathrm{~m} & 0 \mathrm{~m} & 0 \mathrm{~m} \\
50 \mathrm{~m} & 0 \mathrm{~m} & 0 \mathrm{~m} & 0 \mathrm{~m} & 0 \mathrm{~m} \\
100 \mathrm{~m} & 0 \mathrm{~m} & 0 \mathrm{~m} & 0 \mathrm{~m} & 0 \mathrm{~m} \\
200 \mathrm{~m} & 0 \mathrm{~m} & 0 \mathrm{~m} & 0 \mathrm{~m} & 0 \mathrm{~m} \\
300 \mathrm{~m} & 0 \mathrm{~m} & 0 \mathrm{~m} & 0 \mathrm{~m} & 0 \mathrm{~m}\end{array} \\
150 \mathrm{~m}]\end{array}$ & 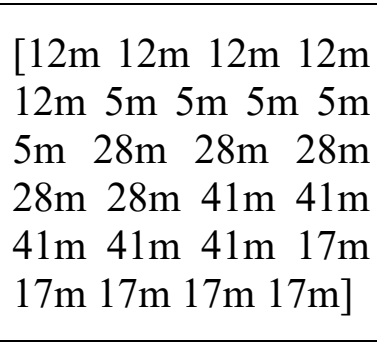 \\
\hline
\end{tabular}

-see Fig. 4(a) of [1], point A- for good channel class case, Topology 3, bad channel class case, Topology 4, and the "LOS" transmission case at $\mathrm{f}=25 \mathrm{MHz}$ and $\mathrm{f}=76 \mathrm{MHz}$, respectively. In Figs. 9(a) and 9(d), each of the aforementioned topologies is accompanied by its corresponding equivalent concatenation of $K$ two-way power divider per each $K$-multiple-branch junction. In Figs 9(b) and 9(e), similar plots are given for the propagation of $\mathrm{DM}_{1}^{\mathrm{MV}}$. In Figs. 9(c) and 9(f), the absolute difference of the channel attenuations between $\mathrm{DM}_{1}^{\mathrm{LV}}$ and $\mathrm{DM}_{1}^{\mathrm{MV}}$ is also drawn with respect to the distance from the transmitting end for the same topologies at $\mathrm{f}=25 \mathrm{MHz}$ and $\mathrm{f}=76 \mathrm{MHz}$, respectively.

From Figs. 9(a)-(e), it is clearly demonstrated that the superimposed attenuation due to the multiple branches at each junction depends on the frequency, the number, and the electrical length of each of these multiple branches. As the branches become longer, 


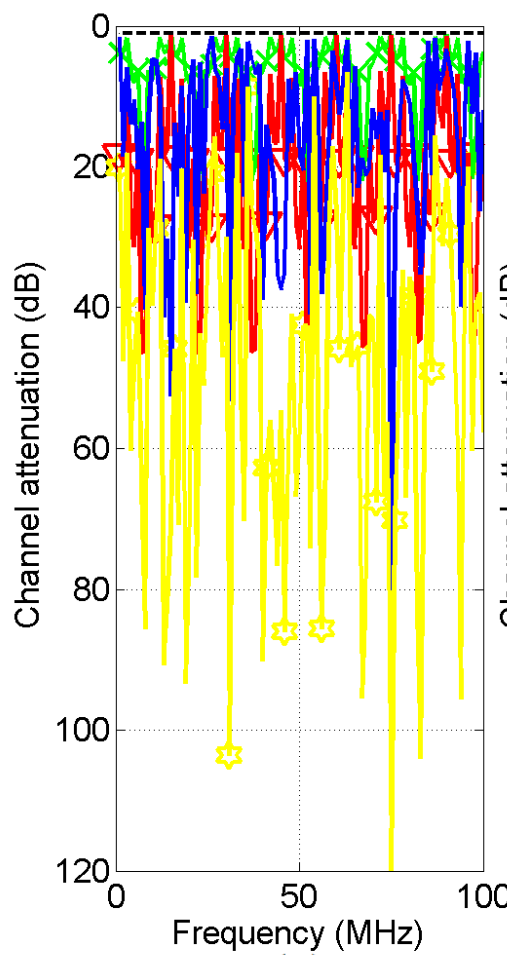

(a)

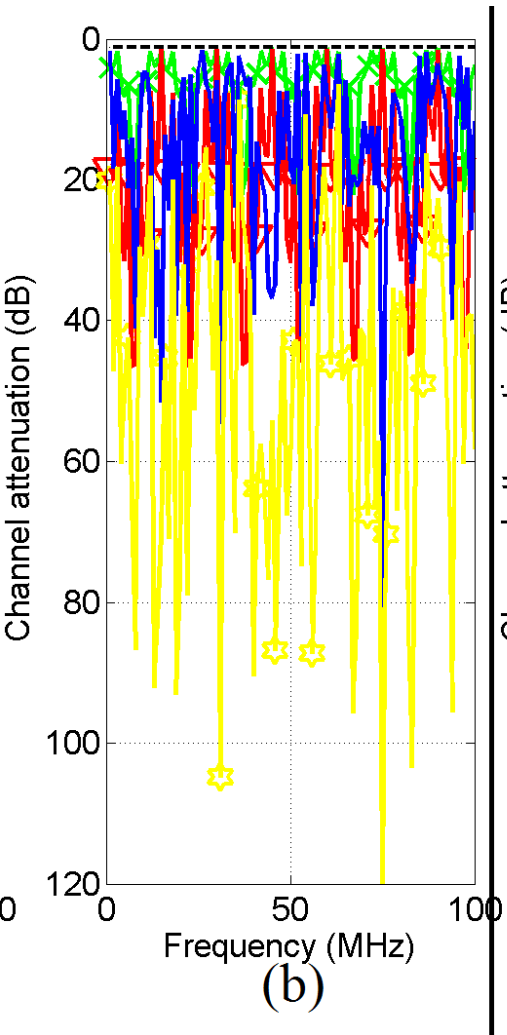

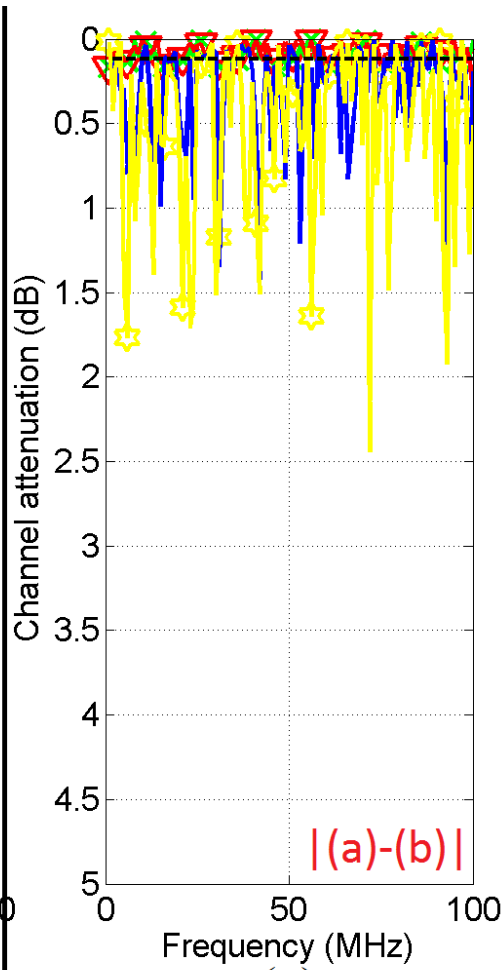

(c)

Figure 8. End-to-end channel attenuation versus frequency for good channel class case $\left({ }^{*}\right)$, Topology $3(\nabla)$, bad channel class case $(-)$, Topology $4(-)$, and "LOS" transmission case (----) when TEP method is applied (the subchannel frequency spacing is equal to $1 \mathrm{MHz}$ ). (a) $\mathrm{DM}_{1}^{\mathrm{LV}}$. (b) $\mathrm{DM}_{1}^{\mathrm{MV}}$. (c) Absolute difference between $\mathrm{DM}_{1}^{\mathrm{LV}}$ and $\mathrm{DM}_{1}^{\mathrm{MV}}$.

the spectral behavior of the BPL networks tends to converge to the spectral behavior of the respective BPL networks with branch terminations matched to the characteristic impedance of the mode examined; say, approximately a $3.01 \mathrm{~dB}$ superimposed attenuation per each single branch or $K \times 3.01 \mathrm{~dB}$ superimposed attenuation per each $K$-branch junction. Actually, the convergence between numerical results and approximation method is better, as the number of branches per junction and the length of branches increase. On the basis of the satisfactory accuracy between numerical results and results from the simplified approximation method, the concatenation of $K$ two-way power divider per each $K$-multiple-branch junction is validated [2], [30]-[32], [53], [55]. This result defines the second circuital approximation of TEP method and, at the same time. Similarly to the first circuital approximation, it is easily understandable by ECE students since power dividers are presented during the Microwave Engineering and Circuit/System Engineering courses. 


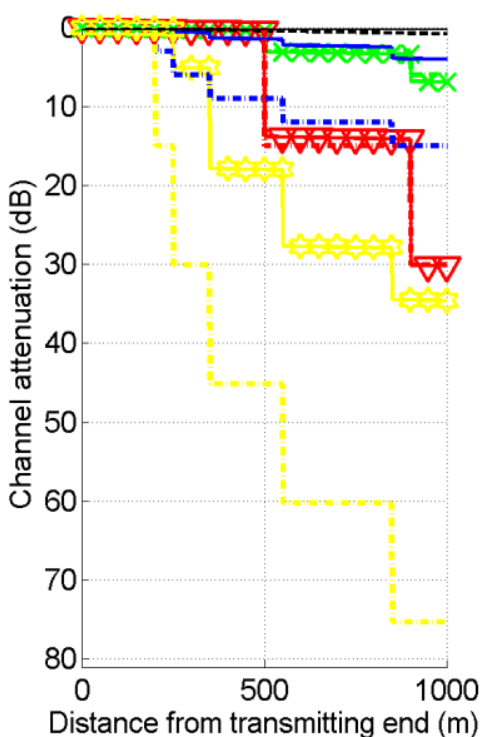

(a)

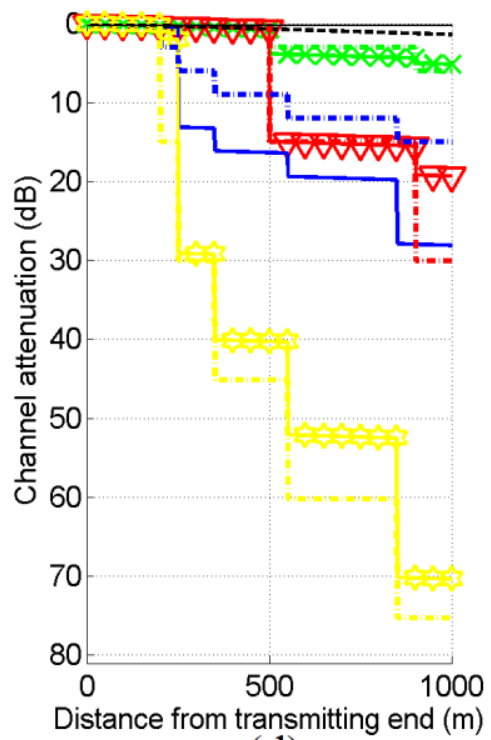

(d)

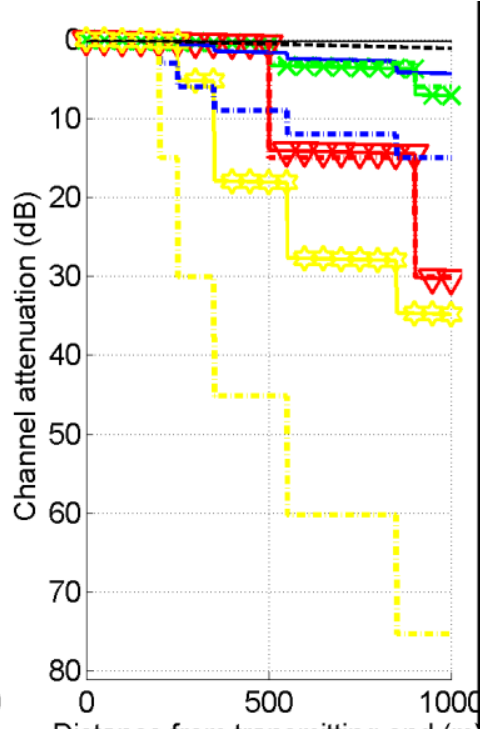

Distance from transmitting end $(\mathrm{m}$

(b)

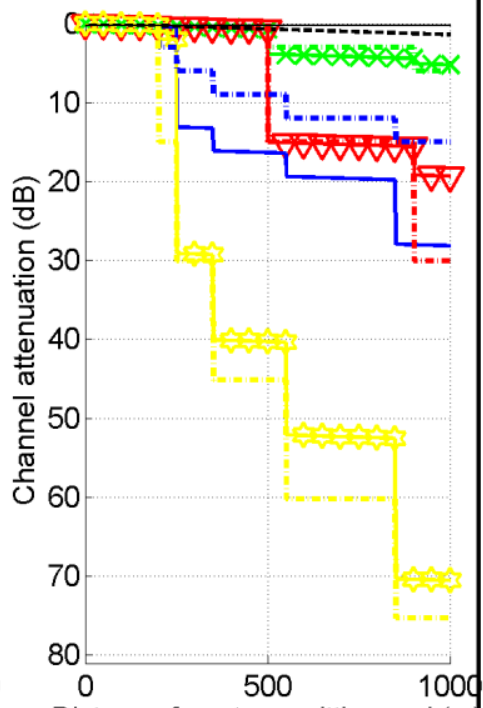

Distance from transmitting end $(\mathrm{m}$

(e)

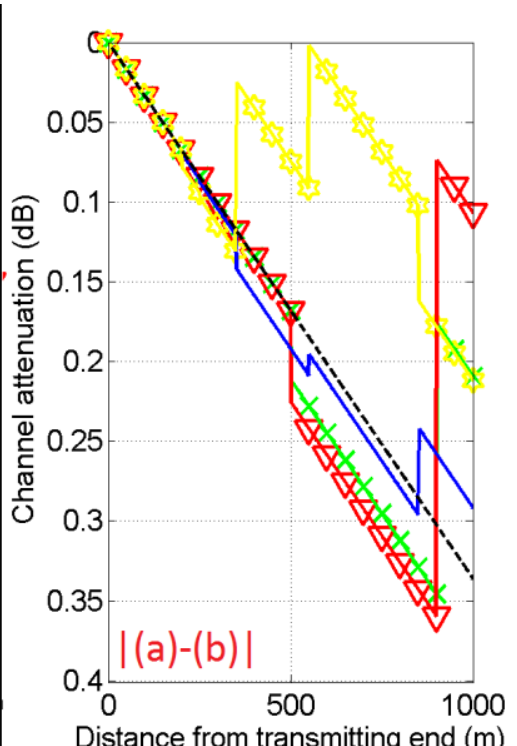

(c)

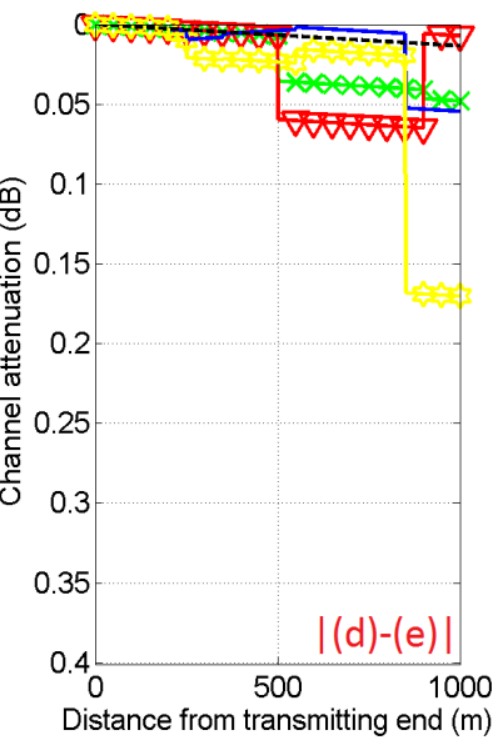

(f)

Figure 9. Channel attenuation versus the distance from the transmitting end -see Fig. 4(a) of [1], point A- for good channel class case $(-\leftarrow)$ with its equivalent concatenation of two-way power dividers $(=--)$ ), Topology $3(\nabla)$ with its equivalent concatenation of two-way power dividers ( $-\boldsymbol{-})$, bad channel class case (-) with its equivalent concatenation of two-way

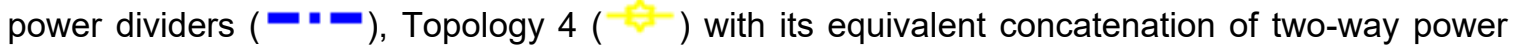
dividers $(-"=)$, and "LOS" transmission case $(---)$ when the TEP method is adopted (the distance span is equal to $1 \mathrm{~m}$ ). (a) $\mathrm{DM}_{1}^{\mathrm{LV}}$ at $\mathrm{f}=25 \mathrm{MHz}$. (b) $\mathrm{DM}_{1}^{\mathrm{MV}}$ at $\mathrm{f}=25 \mathrm{MHz}$. (c) Absolute difference between $\mathrm{DM}_{1}^{\mathrm{LV}}$ and $\mathrm{DM}_{1}^{\mathrm{MV}}$ at $\mathrm{f}=25 \mathrm{MHz}$. (d) $\mathrm{DM}_{1}^{\mathrm{LV}}$ at $\mathrm{f}=76 \mathrm{MHz}$. (e) $\mathrm{DM}_{1}^{\mathrm{MV}}$ at $\mathrm{f}=76 \mathrm{MHz}$. (e) Absolute difference between $\mathrm{DM}_{1}^{\mathrm{LV}}$ and $\mathrm{DM}_{1}^{\mathrm{MV}}$ at $\mathrm{f}=76 \mathrm{MHz}$. 


\section{E. Synopsizing the Comparison Results between Overhead LV/BPL and MV/BPL Topologies - The Common PHY Framework}

Concluding this exhaustive comparative EVD modal analysis concerning the behavior of overhead LV/BPL and MV/BPL distribution power grid, several interesting remarks can be pointed out:

- TEP method can comfortably replace hybrid method for educational purposes. In fact, TEP method maintains the required simplicity so as to be understandable from ECE students without lacking of the basic elements of propagation and transmission analysis that should be highlighted. This result has been verified in overhead LV/BPL and MV/BPL modal channels.

- ECE students can recognize that though determined for $1 \mathrm{~km}$ long LV and MV connections, BPL transmission via the overhead distribution grid exhibits low-loss characteristics regardless of the overhead power grid type favoring the exploitation of LV/BPL and MV/BPL bandwidth.

- The $\mathrm{CM}^{\mathrm{LV}}$ and the $\mathrm{CM}^{\mathrm{MV}}$ exhibit: (i) an almost identical spectral behavior regarding their attenuation coefficients and phase delays as it has already mentioned in Section III -see Figs. 2(b), 2(f), 3(b) and 3(f)-; and (ii) very close end-to-end channel attenuation for a great number of indicative overhead BPL topologies -see Figs. 4(c) and 5(c)-. Hence, the transmission characteristics of only one $\mathrm{CM}^{X V}$-either $\mathrm{CM}^{\mathrm{LV}}$ or $\mathrm{CM}^{\mathrm{MV}}$ - may be examined for both overhead LV/BPL and MV/BPL systems with significant accuracy.

- As to the $\mathrm{DM}^{X V}$, since the $\mathrm{DM}^{\mathrm{LV}} \mathrm{S}$ and $\mathrm{DM}^{\mathrm{MV}}$ s exhibit: (i) an almost identical spectral behavior regarding their attenuation coefficients and phase delays as it has already mentioned in Section III -see Figs. 2(c), 2(d), 2(g), 2(h), 3(c), 3(d), $3(\mathrm{~g})$ and 3(h)-; (ii) very close end-to-end channel attenuation for a plethora of indicative overhead LV/BPL and MV/BPL topologies -see Figs. 4(f), 5(f), 6(f), and 8(c)-; and (iii) identical attenuation discontinuity for a plethora of indicative overhead LV/BPL and MV/BPL topologies either at single-branch junctions -see Figs. 7(c) and 7(f)- or at multi-branch junctions -see Figs. 9(c) and 9(f)-. Thus, the transmission characteristics of only one $\mathrm{DM}^{X V}$-only one of either $\mathrm{DM}^{\mathrm{LV}}$ or $\mathrm{DM}^{\mathrm{MV}}$ - may be examined giving results with excellent accuracy for both overhead LV/BPL and MV/BPL systems.

- As the branches become longer and the number of branches per junction increases, the spectral behavior of the overhead BPL networks tends to converge to the spectral behavior of an equivalent circuit which consists of the concatenation of the $N K_{i}$-two-way power dividers, $i=1, \ldots, N$ where $K_{i}$ is the number of multiples branches at the junction $i, \quad i=1, \ldots, N$ -see Fig. 4(a) of [1], point $A_{i-}$. This approach is a simple channel modelling approximation further facilitating the analysis of overhead LV/BPL and MV/BPL networks.

- Apart from the multiplicity of the various branches encountered along the end-to-end BPL signal propagation, ECE students can identify that the end-to-end channel attenuation in overhead BPL modal channels depends on the frequency, the physical properties of the MTL configurations used, the "LOS" attenuation, and the number, the electrical length, and the terminations of the various branches.

- ECE students can finally realize the common nature between overhead LV/BPL and MV/BPL systems. This permits their common handling under a unified PHY 
framework as it concerns their BPL signal transmission through their power lines. The consideration of only one mode -say $\mathrm{DM}_{1}^{X V}$ - for both overhead LV/BPL and MV/BPL systems defines the final step of the common handling PHY approach of overhead distribution power systems. Anyway, the application of a unified PHY framework in real BPL networks using more sophisticated channel approximation techniques is going to be further analyzed in the oncoming research works [65], [66].

\section{Conclusions}

This companion paper has presented the extension of TEP method that is suitable for the study and the design of overhead LV/BPL and MV/BPL networks from ECE students. This paper has focused on the perspective of common handling of overhead LV/BPL and MV/BPL distribution power systems during BPL signal transmission analysis. This approach offers a valuable tool towards the unified BPL distribution network design when different topologies occur.

Apart from the educational character of this paper, it has been demonstrated that the broadband transmission capability of such networks depends on the frequency, the physical properties of the overhead MTL configuration used, the end-to-end -"LOS"distance, and the number, the electrical length, the terminations, and the multiplicity of the branches along the end-to-end BPL signal propagation. Furthermore, under the aegis of the unified PHY framework, a simple approximation suitable for the modelling of overhead BPL distribution networks when multiple branches at the same junction occur has been proposed. The simplified approach of TEP method suggests that the spectral behavior of overhead BPL distribution power networks may be satisfactorily described by using equivalent circuits which consist of concatenations of two-way power dividers.

Finally, the results demonstrate to ECE students the low-loss nature of overhead BPL systems over a $1 \mathrm{~km}$ repeater span well beyond $100 \mathrm{MHz}$. Concluding this paper, ECE students realize that overhead distribution power lines can operate as a promising broadband last mile technology permitting the further exploitation of overhead BPL bandwidth regardless of the overhead power grid type and the overhead power grid topology.

\section{Conflicts of Interest}

The author declares that there is no conflict of interests regarding the publication of this paper.

\section{References}

[1] A. G. Lazaropoulos, "Designing Broadband over Power Lines Networks Using the Techno-Economic Pedagogical (TEP) Method - Part I: Overhead High Voltage Networks and Their Capacity Characteristics," Trends in Renewable Energy, vol. 1, no. 1, pp. 16-42, Mar. 2015. DOI: 10.17737/tre.2015.1.1.002

[2] A. G. Lazaropoulos and P. G. Cottis, "Transmission characteristics of overhead medium voltage power line communication channels," IEEE Trans. Power Del., vol. 24, no. 3, pp. 1164-1173, Jul. 2009. DOI: 10.1109/tpwrd.2008.2008467

[3] A. G. Lazaropoulos, "Towards Modal Integration of Overhead and Underground Low-Voltage and Medium-Voltage Power Line Communication Channels in the Smart Grid Landscape: Model Expansion, Broadband Signal Transmission 
Characteristics, and Statistical Performance Metrics (Invited Paper)," ISRN Signal Processing, vol. 2012, Article ID 121628, pp. 1-17, 2012. DOI: $10.5402 / 2012 / 121628$

[4] A. G. Lazaropoulos and P. G. Cottis, "Capacity of overhead medium voltage power line communication channels," IEEE Trans. Power Del., vol. 25, no. 2, pp. $723-$ 733, Apr. 2010. DOI: 10.1109/tpwrd.2009.2034907

[5] A. G. Lazaropoulos, "Review and Progress towards the Common Broadband Management of High-Voltage Transmission Grids: Model Expansion and Comparative Modal Analysis," ISRN Electronics, vol. 2012, Article ID 935286, pp. 1-18, 2012. DOI: 10.5402/2012/935286

[6] A. G. Lazaropoulos, "Broadband Transmission Characteristics of Overhead HighVoltage Power Line Communication Channels," Progress in Electromagnetics Research B, vol. 36, pp. 373-398, 2012. DOI: 10.2528/PIERB11091408

[7] A. G. Lazaropoulos, "Broadband Transmission and Statistical Performance Properties of Overhead High-Voltage Transmission Networks (Invited Paper)," Hindawi Journal of Computer Networks and Commun., vol. 2012, Article ID 875632, pp. 1-16, 2012. DOI: 10.1155/2012/875632

[8] A. G. Lazaropoulos, "Green Overhead and Underground Multiple-Input MultipleOutput Medium Voltage Broadband over Power Lines Networks: Energy-Efficient Power Control," Springer Journal of Global Optimization, 57(3), 997-1024, 2013. DOI: $10.1007 / \mathrm{s} 10898-012-9988-y$

[9] M. U. Rehman, S. Wang, Y. Liu, S. Chen, X. Chen, and C. G. Parini, "Achieving High Data Rate in Multiband-OFDM UWB Over Power-Line Communication System," IEEE Trans. on Power Del., vol. 27, no. 3, pp. 1172-1177, Jul. 2012. DOI: 10.1109/TPWRD.2012.2193902

[10] A. M. Sarafi, G. I. Tsiropoulos, and P. G. Cottis, "Hybrid Wireless-Broadband over Power Lines: A Promising Broadband Solution in Rural Areas," IEEE Comm. Mag., pp. 140-147, Nov. 2009. DOI: 10.1109/MCOM.2009.5307478

[11] G. N. S. Prasanna, A. Lakshmi, S. Sumanth, V. Simha, J. Bapat, and G. Koomullil, "Data Communication over the Smart Grid," in Proc. IEEE Int. Symp. Power Line Communications and Its Applications, Dresden, Germany, Mar./Apr. 2009, pp. 273-279. DOI: 10.1109/ISPLC.2009.4913442

[12] S. Galli, A. Scaglione, and Z. Wang, "For the grid and through the grid: the role of power line communications in the smart grid," in Proc. IEEE, vol. 99, no. 6, pp. 998-1027, Jun. 2011.

[13] S. Liu and L. J. Greenstein, "Emission characteristics and interference constraint of overhead medium-voltage broadband power line (BPL) systems," in Proc. IEEE Global Telecommunications Conf., New Orleans, LA, USA, Nov./Dec. 2008, pp. 15. DOI: 10.1109/GLOCOM.2008.ECP.560

[14] P. Amirshahi and M. Kavehrad, "High-frequency characteristics of overhead multiconductor power lines for broadband communications," IEEE J. Sel. Areas Commun., vol. 24, no. 7, pp. 1292-1303, Jul. 2006. DOI: $10.1109 /$ jsac. 2006.874399

[15] A. G. Lazaropoulos, "Review and Progress towards the Capacity Boost of Overhead and Underground Medium-Voltage and Low-Voltage Broadband over Power Lines Networks: Cooperative Communications through Two- and Three-Hop Repeater Systems," ISRN Electronics, vol. 2013, Article ID 472190, pp. 1-19, 2013. DOI: 10.1155/2013/472190 
[16] S. Galli, and Oleg Logvinov, "Recent developments in the standardization of power line communications within the IEEE," IEEE Communications Magazine, vol. 46, no. 7, pp. 64-71, 2008. DOI: 10.1109/MCOM.2008.4557044

[17] P. S. Henry, "Interference characteristics of broadband power line communication systems using aerial medium voltage wires," IEEE Commun. Mag., vol. 43, no. 4, pp. 92-98, Apr. 2005. DOI: 10.1109/MCOM.2005.1421910

[18] J. Anatory, N. Theethayi, R. Thottappillil, M. M. Kissaka, and N. H. Mvungi, "The effects of load impedance, line length, and branches in typical low-voltage channels of the BPLC systems of developing countries: transmission-line analyses," IEEE Trans. Power Del., vol. 24, no. 2, pp. 621-629, Apr. 2009. DOI: 10.1109/TPWRD.2008.923395

[19] T. Sartenaer, "Multiuser communications over frequency selective wired channels and applications to the powerline access network" Ph.D. dissertation, Univ. Catholique Louvain, Louvain-la-Neuve, Belgium, Sep. 2004.

[20] T. Calliacoudas and F. Issa, "'Multiconductor transmission lines and cables solver," An efficient simulation tool for plc channel networks development," presented at the IEEE Int. Conf. Power Line Communications and Its Applications, Athens, Greece, Mar. 2002.

[21] C. R. Paul, Analysis of Multiconductor Transmission Lines. New York: Wiley, 1994.

[22] T. Sartenaer and P. Delogne, "Deterministic modelling of the (Shielded) outdoor powerline channel based on the multiconductor transmission line equations," IEEE J. Sel. Areas Commun., vol. 24, no. 7, pp. 1277-1291, Jul. 2006. DOI: $10.1109 /$ jsac. 2006.874423

[23] S. Galli and T. Banwell, "A deterministic frequency-domain model for the indoor power line transfer function," IEEE J. Sel. Areas Commun., vol. 24, no. 7, pp. 1304-1316, Jul. 2006. DOI: 10.1109/jsac.2006.874428

[24] A. G. Lazaropoulos and P. G. Cottis, "Broadband transmission via underground medium-voltage power lines-Part II: capacity," IEEE Trans. Power Del., vol. 25, no. 4, pp. 2425-2434, Oct. 2010. DOI: 10.1109/tpwrd.2010.2052113

[25] P. Amirshahi, "Broadband access and home networking through powerline networks" Ph.D. dissertation, Pennsylvania State Univ., University Park, PA, May 2006.

[26] H. Meng, S. Chen, Y. L. Guan, C. L. Law, P. L. So, E. Gunawan, and T. T. Lie, "Modeling of transfer characteristics for the broadband power line communication channel," IEEE Trans. Power Del., vol. 19, no. 3, pp. 1057-1064, Jul. 2004. DOI: 10.1109/tpwrd.2010.2048929

[27] OPERA1, D44: Report presenting the architecture of plc system, the electricity network topologies, the operating modes and the equipment over which PLC access system will be installed, IST Integr. Project No 507667, Dec. 2005.

[28] DLC+VIT4IP, D1.2: Overall system architecture design DLC system architecture. FP7 Integrated Project No 247750, Jun. 2010.

[29] K. Dostert, Powerline Communications. Upper Saddle River, NJ: Prentice-Hall, 2001.

[30] A. G. Lazaropoulos and P. G. Cottis, "Broadband transmission via underground medium-voltage power lines-Part I: transmission characteristics," IEEE Trans. Power Del., vol. 25, no. 4, pp. 2414-2424, Oct. 2010. DOI: 10.1109/tpwrd.2010.2048929 
[31] A. G. Lazaropoulos, "Towards Broadband over Power Lines Systems Integration: Transmission Characteristics of Underground Low-Voltage Distribution Power Lines," Progress in Electromagnetics Research B, vol. 39, pp. 89-114, 2012. DOI: 10.2528/PIERB12012409

[32] A. G. Lazaropoulos, "Factors Influencing Broadband Transmission Characteristics of Underground Low-Voltage Distribution Networks," IET Commun., vol. 6, no. 17, pp. 2886-2893, Nov. 2012. DOI: 10.1049/iet-com.2011.0661

[33] A. G. Lazaropoulos, "Deployment Concepts for Overhead High Voltage Broadband over Power Lines Connections with Two-Hop Repeater System: Capacity Countermeasures against Aggravated Topologies and High Noise Environments," Progress in Electromagnetics Research B, vol. 44, pp. 283-307, 2012. DOI: 10.2528/PIERB12081104

[34] A. G. Lazaropoulos, "Underground Distribution BPL Connections with $(\mathrm{N}+1)$-hop Repeater Systems: A Novel Capacity Mitigation Technique," Elsevier Computers and Electrical Engineering, vol. 40, pp. 1813-1826, 2014. DOI: 10.1016/j.compeleceng.2014.06.001

[35] M. Gebhardt, F. Weinmann, and K. Dostert, "Physical and regulatory constraints for communication over the power supply grid," IEEE Commun. Mag., vol. 41, no. 5, pp. 84-90, May 2003. DOI: 10.1109/mcom.2003.1200106

[36] A. G. Lazaropoulos, "Broadband over Power Lines Systems Convergence: Multiple-Input Multiple-Output Communications Analysis of Overhead and Underground Low-Voltage and Medium-Voltage BPL Networks," ISRN Power Engineering, vol. 2013, Article ID 517940, 30 pages, 2013. DOI: $10.1155 / 2013 / 517940$

[37] P. Amirshahi and M. Kavehrad, "Medium voltage overhead power-line broadband communications; Transmission capacity and electromagnetic interference," in Proc. IEEE Int. Symp. Power Line Commun. Appl., Vancouver, BC, Canada, Apr. 2005, pp. 2-6. DOI: 10.1109/ISPLC.2005.1430454

[38] M. Götz, M. Rapp, and K. Dostert, "Power line channel characteristics and their effect on communication system design," IEEE Commun. Mag., vol. 42, no. 4, pp. 78-86, Apr. 2004. DOI: 10.1109/mcom.2004.1284933

[39] T. A. Papadopoulos, G.K. Papagiannis, and D.P. Labridis, "A generalized model for the calculation of the impedances and admittances of overhead power lines above stratified earth." Electric Power Systems Research, 80(9), 1160-1170. DOI: 10.1016/j.epsr.2010.03.009

[40] T. A. Papadopoulos, C. G. Kaloudas, and G. K. Papagiannis, "A multipath channel model for PLC systems based on nodal method and modal analysis," in Proc. 2007 IEEE Int. Symp. Power Line Communications and Its Applications (ISPLC'07), Pisa, Italy, Mar. 2007, pp. 278-283. DOI: 10.1109/ISPLC.2007.371137

[41] T. A. Papadopoulos, B. D. Batalas, A. Radis, and G. K. Papagiannis, "Medium voltage network PLC modeling and signal propagation analysis," in Proc. 2007 IEEE Int. Symp. Power Line Communications and its Applications (ISPLC'07), Pisa, Italy, Mar. 2007, pp. 284-289. DOI: 10.1109/ISPLC.2007.371138

[42] F. Issa, D. Chaffanjon, E. P. de la Bâthie, and A. Pacaud, "An efficient tool for modal analysis transmission lines for PLC networks development," presented at the IEEE Int. Conf. Power Line Communications and Its Applications, Athens, Greece, Mar. 2002. 
[43] J. Anatory and N. Theethayi, "On the efficacy of using ground return in the broadband power-line communications-A transmission-line analysis," IEEE Trans. Power Del., vol. 23, no. 1, pp. 132-139, Jan. 2008. DOI: 10.1109/TPWRD.2007.910987

[44] A. I. Chrysochos, T. A. Papadopoulos, and G. K. Papagiannis, "Enhancing the frequency-domain calculation of transients in multiconductor power transmission lines," Electric Power Systems Research, vol. 122, pp. 56-64, 2015. DOI: 10.1016/j.epsr.2014.12.024

[45] M. D'Amore and M. S. Sarto, "A new formulation of lossy ground return parameters for transient analysis of multiconductor dissipative lines," IEEE Trans. Power Del., vol. 12, no. 1, pp. 303-314, Jan. 1997. DOI: 10.1109/61.568254

[46] M. D'Amore and M. S. Sarto, "Simulation models of a dissipative transmission line above a lossy ground for a wide-frequency range-Part I: Single conductor configuration," IEEE Trans. Electromagn. Compat., vol. 38, no. 2, pp. 127-138, May 1996. DOI: 10.1109/15.494615

[47] M. D'Amore and M. S. Sarto, "Simulation models of a dissipative transmission line above a lossy ground for a wide-frequency range-Part II: Multi-conductor configuration," IEEE Trans. Electromagn. Compat., vol. 38, no. 2, pp. 139-149, May 1996. DOI: 10.1109/15.494616

[48] W. H. Wise, "Propagation of High Frequency Currents in Ground Return Circuits," Proc. Inst. Radio Eng., vol. 22, pp. 522-527, Apr., 1934. DOI: 10.1109/JRPROC.1934.225868

[49] W. H. Wise, "Potential coefficients for ground return circuits," Bell Syst. Tech. J., vol. 27, pp. 365-371, Apr., 1948. DOI: 10.1002/j.1538-7305.1948.tb00913.x

[50] S. Barmada, A. Musolino, and M. Raugi, "Innovative model for time-varying power line communication channel response evaluation," IEEE J. Sel. Areas Commun., vol. 24, no. 7, pp. 1317-1326, Jul. 2006. DOI: 10.1109/JSAC.2006.874426

[51] M. Zimmermann and K. Dostert, "A multipath model for the powerline channel," IEEE Trans. Commun., vol. 50, no. 4, pp. 553-559, Apr. 2002. DOI: $10.1109 / 26.996069$

[52] D. Sabolić, R. Malarić, and A. Bažant, "A Practical Method for Extraction of HighFrequency Parameters of Distribution Cables," IEEE Trans. on Power Del., vol. 27, no. 4, pp. 1877-1884, Oct. 2012. DOI: 10.1109/TPWRD.2012.2211899

[53] J. Anatory, N. Theethayi, R. Thottappillil, M. M. Kissaka, and N. H. Mvungi, "The influence of load impedance, line length, and branches on underground cable Power-Line Communications (PLC) systems," IEEE Trans. Power Del., vol. 23, no. 1, pp. 180-187, Jan. 2008. DOI: 10.1109/TPWRD.2007.911020

[54] OPERA1, D5: Pathloss as a function of frequency, distance and network topology for various LV and MV European powerline networks. IST Integrated Project No 507667, Apr. 2005.

[55] J. Anatory, N. Theethayi, and R. Thottappillil, "Power-line communication channel model for interconnected networks-Part II: Multiconductor system," IEEE Trans. Power Del., vol. 24, no. 1, pp. 124-128, Jan. 2009. DOI: 10.1109/TPWRD.2008.2005681

[56] P. A. A. F. Wouters, P. C. J. M. van der Wielen, J. Veen, P. Wagenaars, and E. F. Steennis, "Effect of cable load impedance on coupling schemes for MV power line 
communication," IEEE Trans. Power Del., vol. 20, no. 2, pt. 1, pp. 638-645, Apr. 2005. DOI: 10.1109/TPWRD.2005.844334

[57] L. M. Kuhn, S. Berger, I. Hammerström, and A. Wittneben, "Power line enhanced cooperative wireless communications," IEEE J. Sel. Areas Commun., vol. 24, no. 7, pp. 1401-1410, Jul. 2006. DOI: 10.1109/JSAC.2006.874407

[58] Y. Xiaoxian, Z. Tao, Z. Baohui, Y. Fengchun, D. Jiandong, and S. Minghui, "Research of impedance characteristics for medium-voltage power networks," IEEE Trans. Power Del., vol. 22, no. 2, pp. 870-878, Apr. 2007. DOI: 10.1109/TPWRD.2006.881573

[59] Y. Xiaoxian, Z. Tao, Z. Baohui, N. Xu, W. Guojun, and D. Jiandong, "Investigation of transmission properties on $10-\mathrm{kV}$ medium voltage power lines - part I: general properties," IEEE Trans. on Power Del., vol. 22, no. 3, pp. 1446-1454, 2007. DOI: 10.1109/TPWRD.2007.900290

[60] Z. Tao, Y. Xiaoxian, Z. Baohui, C. Jian, Y. Zhi, and T. Zhihong, "Research of noise characteristics for $10-\mathrm{kV}$ medium-voltage power lines," IEEE Trans. on Power Del., vol. 22, no. 1, pp. 142-150, 2007. DOI: 10.1109/TPWRD.2006.881414

[61] J. Anatory, N. Theethayi, R. Thottappillil, M. M. Kissaka, and N. H. Mvungi, “An experimental validation for Broadband Power-Line Communication (BPLC) model," IEEE Trans. Power Del., vol. 23, no. 3, pp. 1380-1383, Jul. 2008. DOI: 10.1109/TPWRD.2008.916739

[62] J. Anatory, N. Theethayi, R. Thottappillil, M. M. Kissaka, and N. H. Mvungi, "Broadband power-line communication channel model: Comparison between theory and experiments," in Proc. IEEE Int. Symp. Power Line Communications and Its Applications, Jeju Island, Korea, Apr. 2008, pp. 322-324. DOI: 10.1109/ISPLC.2008.4510447

[63] A. G. Lazaropoulos, "Numerical Evaluation of Broadband Transmission Characteristics of Underground Low-Voltage Networks - Introducing TechnoPedagogical (TP) Method," Elsevier Int. Journal of Electrical Power \& Energy Systems, vol. 55, pp. 253-260, 2014. DOI: 10.1016/j.ijepes.2013.09.009

[64] T. A. Papadopoulos, A. I. Chrysochos, A. I. Nousdilis, and G. K. Papagiannis, "Simplified measurement-based black-box modeling of distribution transformers using transfer functions," Electric Power Systems Research, vol. 121, pp. 77-88, 2015. DOI: 10.1016/j.epsr.2014.12.003

[65] I. C. Demetriou, "Algorithm 742: L2CXFT: a Fortran subroutine for least-squares data fitting with nonnegative second divided differences," ACM Transactions on Mathematical Software (TOMS), vol. 21, no. 1, pp. 98-110, 1995. DOI: 10.1145/200979.201039

[66] S. S. Papakonstantinou and I. C. Demetriou, "Data Engineering by the Best 11 Convex Data Fitting Method," in Proceedings of the World Congress on Engineering, vol. 1, 2014.

Article copyright: (C) 2015 Athanasios G. Lazaropoulos. This is an open access article distributed under the terms of the Creative Commons Attribution 4.0 International License, which permits unrestricted use and distribution provided the original author and source are credited. 